CIRJE-F-372

Public Debt and Economic Growth in an Aging Japan

Toshihiro Ihori

University of Tokyo

Ryuta Ray Kato

International University of Japan

Masumi Kawade

Niigata University

Shun-ichiro Bessho

Ministry of Finance, Japanese Government

September 2005

CIRJE Discussion Papers can be downloaded without charge from:

http://www.e.u-tokyo.ac.jp/cirje/research/03research02dp.html

Discussion Papers are a series of manuscripts in their draft form. They are not intended for circulation or distribution except as indicated by the author. For that reason Discussion Papers may not be reproduced or distributed without the written consent of the author. 


\title{
Public Debt and Economic Growth
}

\section{in an Aging Japan*}

\author{
Toshihiro Ihori \\ Faculty of Economics, University of Tokyo \\ Ryuta Ray Kato \\ Graduate School of International Relations, International University of Japan \\ Masumi Kawade \\ Faculty of Economics, Niigata University \\ Shun-ichiro Bessho ${ }^{\dagger}$ \\ Policy Research Institute, Ministry of Finance, Japanese Government
}

July 29,2005

\footnotetext{
${ }^{*}$ We would like to thank Robert Dekle and Toshiki Tomita for their valuable comments. We also thank all participants at the IMF-MOF conference held on 27-28 June 2005 in Tokyo for their comments. In particular we would like to express our gratitude to Robert Dekle and David Weinstein for their detailed comments on an earlier version, all of which, we believe, have improved our paper. This paper does not necessarily reflect the views of Ministry of Finance, Japanese Government. The usual disclaimer applies.

${ }^{\dagger}$ Economist, Policy Research Institute, Ministry of Finance, Japanese Government. 3-1-1, Kasumigaseki, Chiyoda-ku, Tokyo 100-8940, Japan. E-mail: shunitirou.bessho@mof.go.jp
} 


\begin{abstract}
This paper examines the effects of the demographic change and the government debt policy in Japan on economic growth and economic welfare, particularly by taking into account the existing public pension scheme as well as national medical expenditure through the existing public health insurance, where a computational overlapping generations model is used within a general equilibrium context. One of the main results of this paper is that the tax burden (GDP) ratio will increase up to about $36 \%$, and the social security burden (GDP) ratio will increase up to $23.3 \%$ in 2050, even though the government tries to have a positive primary balance by 2010 . The ratio of public health insurance benefits to GDP is expected to increase at $1 \%$ every 10 years, and the ratio will be around $9.6 \%$ in 2050 . The 2004 public pension reform will successfully result in a 13 point decrease in the contribution rate from $36.44 \%$ to $23.53 \%$, and reduce the social security burden (GDP) ratio by about 8 points from $23.27 \%$ to $15.02 \%$ in 2050 , compared with the benchmark case.
\end{abstract}

JEL: H55, E27

Key Words: government deficits, an aging population, public pension scheme, public health insurance, intergenerational redistribution, overlapping generations model, simulation 


\section{Introduction}

This paper examines the effects of the demographic change and the government debt policy in Japan on economic growth and economic welfare, particularly by taking into account the existing public pension scheme as well as national medical expenditure through the existing public health insurance, where a computational overlapping generations model is used within a general equilibrium context.

One of the main features of this paper is to incorporate medical expenditure through the existing public health insurance into the existing literature (Kawade et al. 2005, and Kato 2002a, 2002b), where the computational overlapping generations model has been used within a general equilibrium context in order to discuss several future government policies.

As has been pointed out by several papers (Iwamoto 2004, Tokita 2002), a rapid aging population in Japan will result in a successive increase in national medical expenditure through the existing public health insurance as well as in a rapid increase in the contribution rate of the existing pay-as-you-go public pension scheme provided that the existing systems are maintained in the future. From the individual's point of view, the effect of an aging population would be very important, since an aging population induces an increase in the premium of the public health insurance due to the reason that the amount of public medical insurance benefits to the elder people over 70 years old would be more than 4 times as much as other cohorts. The fact that the elder people possibly needs highly medical thus more expensive equipment/treatments results in the elder people being more "expensive" than other cohorts. Thus, the technical progress in medical science furthermore increases national medical expenditure with an aging population.

All data used in this paper has been based on SNA. Some data was obtained from other sources, but they have been manipulated in order to be consistent with SNA by using relevant SNA data. Outstanding government debts and a public pension fund are taken into account, both of which were obtained from SNA. The public pension fund is considered separately from outstanding government debts, and in this sense the government deficits are given in gross values in this $\operatorname{paper}^{(1)}$.

\footnotetext{
${ }^{(1)}$ In SNA the figures of governments debts are given in net values of central and local governments debts, where financial assets owned by governments are taken into account. Thus, since our paper uses the SNA data, financial assets owned by governments are incorporated into our analysis.
} 
It is interesting to note that Broda and Weinstein (2004) explored the Japanese government deficits in net values by integrating the general account and the social security account. In the actual Japanese budget system, except a certain amount of transfers from a general government account to a public pension account, the general government account and the public pension account are separately financed, and each budget is fundamentally independent. Especially, the government would not be allowed to pay outstanding government debts back by using the accumulated public pension fund without an agreement on fiscal consolidation of both accounts in the Japanese society, and under the current budget system the discussion based on net values would mislead us as to the evaluation of current as well as future government policies. Thus, treatment of both accounts as an integrated one, or a discussion based on net values, would not reflect the actual system. In this sense, gross values of outstanding government deficits are $\operatorname{used}^{(2)}$.

This paper also differs from Broda and Weinstein (2004) in the following important aspects: This paper incorporates the optimal behavior of each agent within a intertemporal general equilibrium framework, and thus, several channels to affect key variables such as interest rates, savings and GDP are taken into account. In particular the interest rate and GDP are both endogenously determined through the optimal behavior of each agent.

On the future population, the latest version of Projection of Future Population in Japan (Shourai-Jinko-Suikei 2002) has been used for the future demography in our simulation under the assumption that fertility rates and mortality rates are both constant from 2100 , and thus the future population gradually converges to a new steady state.

Since the future population structure substantially affects savings particularly at an aggregated level, endogeneity of the interest rate in the capital market as well as GDP in the goods market with the conventional aggregated production function is crucial. The interest rate is endogenously determined in the capital market, where outstanding government bonds, a public pension fund, and aggregated private savings are all taken into account consistently.

Endogeneity of GDP also plays an important role, since the rapid demographic change in the

\footnotetext{
${ }^{(2)}$ Although all discussions in this paper will be given based on gross values, the calculated net value of government deficits in 2002 is around 60\%, which is close to the value in Broda and Weinstein (2002). The main reason why our simulation results are much more severe would come from different assumptions on the difference between the interest rate and the economic growth rate, particularly from their optimistic assumption on the economic growth.
} 
future in Japan obviously affects labor force and aggregated savings. The change in aggregated savings affects private capital in the capital market, and thus the endogeneity of the interest rate and GDP can capture these effects. Japan will not have experienced not only high and rapid population aging but also a decrease in the total population in the future. If the future government deficits due to this unexperienced demographic change are anticipated, then the optimal behavior of each agent in relevant markets should be considered in order to take into account these effects.

Technological progress of private production also plays a very important role. A $1 \%$ difference in an annual rate of technological progress results in a substantial difference in future GDP as pointed out by Kato (2002d). Kato (2002d) showed that an introduction of $0.5 \%$ dimishing growth of technological progress for 40 years eventuated in a $8.4 \%$ increase in per capita income in a new steady state, and also that $1.0 \%$ dimishing growth achieved a $18.3 \%$ increase in per capita income. Since the difference between the interest rate and GDP obviously induces different evaluations of future deficits policies, a very careful attention should be paid to the assumption on technological progress. As will be described later, technological progress in Japan measured by the Solow residual in the past two decades has been around zero $\%^{(3)}$, and thus the value of technological progress in our benchmark simulation is assumed to be zero. However, note also that other cases of positive rates of technological progress in the future have been investigated, since the difference in the assumption of technological progress does matter particularly in terms of the difference in the gap between the interest rate and GDP. Although the zero assumption on technical progress reflects the actual aspect for the last two decades, the assumption that zero technological progress continues in the future as well might not be necessary. Thus, other cases with $0.5 \%$ as well as $1.0 \%$ technological progress will also be explored.

A gap between the interest rate and the growth rate in this paper is much bigger than that in Broda and Weinstein (2004), which results in different results between in their optimistic paper and in our pessimistic paper.

The results obtained in this paper are summarized as follows: One of the main results of this paper is that the tax burden (GDP) ratio will increase up to about $36 \%$, and the social security

\footnotetext{
${ }^{(3)}$ Our recalculaiton of the Solow residual does not take into account the effect of public capital on technological progress, and an inclusion of the effect of public capital would obviously result in an upward shift of technological progress. Kawade, Bessho and Kato (2005) and Kato (2002b, c, d) discuss the effect of public capital on private production.
} 
burden (GDP) ratio will increase up to $23.3 \%$ in 2050, even though the government tries to have a positive primary balance by 2010. Note that all ratios presented in this paper are based on GDP, and the above figures do not coincide with the actual figures, which are usually defined on national income. If our simulated values of the ratios are re-calculated based on national income, the ratios become larger. However, the result that high burdens on future generations cannot be avoided does not change, since the difference between the values in the conventional definition and the values in our definition does not change the rapid increasing trend of the ratios.

The national burden ratio to GDP, defined by the sum of the tax burden (GDP) ratio and the social security burden (GDP) ratio, will be around $59 \%$ in 2050 in the benchmark case. This figure can also be shown in the conventional definition, the national income burden ratio. The national income burden ratio is defined as the ratio to national income, and it will have to be around $80 \%$ in 2050. Our striking result is that if the government wants to have a positive primary balance by 2010 , then the future burden should be very high, implying that the current financial situation facing the Japanese government in terms of governments deficits is very dangerous. If the government postpones the timing to pay its deficits back, then the situation would be worse due to more interest payment incurred by the huge amount of outstanding government debts.

Future high burdens can be explained by the reason why future GDP will decrease due to a substantial decrease in labor force and forecasted zero technological progress, which was based on the calculation of the Solow residual of the past two decades.

Another striking result is that future technological progress will result in more future tax burdens, although an expansion of technological progress increases future GDP. In our simulation an expansion of future technological progress results in an increase in the future equilibrium interest rate, thus inducing an increase in the future consumption tax rate to finance more interest payments incurred by government debts. The gaps between the interest rate and the GDP growth rate become bigger rather than smaller.

An aging population will result in an increase in the total amount of the public pension benefits as well as the total amount of the public health insurance benefits, even though the amount of per capita benefits are fixed at the 2002 level in the future, if the current scheme is 
maintained. The ratio of public health insurance benefits to GDP is expected to increase at 1 $\%$ every 10 years, and the ratio will be around $9.6 \%$ in 2050. The 2004 public pension reform will successfully result in a 13 point decrease in the contribution rate from $36.44 \%$ to $23.53 \%$, and reduce the social security burden ratio to GDP by 8 points from $23.27 \%$ to $15.02 \%$ in 2050 , compared with the benchmark case.

This paper is organized as follows: The next section summarizes the sustainability problem, and Section 3 presents the basic model employed in the simulation analysis. Section 4 shows the data and parameters used in the simulation analysis, and Section 5 evaluates the simulation results. Section 6 summarizes and concludes the paper.

\section{Sustainability Problem}

\subsection{Largest Sustainable Debt}

Japan is suffering from large government deficits. This is largely due to a slowdown of economic growth in recent years. When national income does not grow much, tax revenue will not increase either. On the contrary, public spending and transfer payments have been gradually raised due to political pressures of interest groups, resulting in large budget deficits. The question of whether Japan's fiscal policy has been sustainable in the sense of being consistent with an intertemporal budget constraint has long been concerned.

In order to explore theoretically the determinants of the largest amount of per capita debt that is consistent with competitive equilibrium $b *$, consider a simple pure-exchange two-period overlapping generations economy with constant population, which is consistent with Ricardian debt neutrality. The growth rate of population, $n$, is assumed to be zero. See Samuelson (1958) and Azariadis (1993). The per-capita saving function of the younger generation $s()$ is given by

$$
s\left(r_{t+1}\right)=b_{t},
$$

where $r$ is the interest rate and $b$ is per capita debt. It is assumed that savings are increasing with the rate of interest. $\frac{\partial s}{\partial r}>0$. Then, from (1) we have 


$$
r_{t+1}=r\left(b_{t}\right)
$$

The government budget constraint at time $t+1$ is given by

$$
b_{t+1}=\left(1+r_{t+1}\right) b_{t}+g_{t+1}-\tau_{t+1}
$$

where $g$ is public spending and $\tau$ is tax revenues. The primary deficit $q$ is defined as the difference between $g$ and $\tau$. Suppose for simplicity $q=0$. Then, substituting (2) into (3), we get

$$
b_{t+1}=\left[1+r\left(b_{t}\right)\right] b_{t}
$$

Figure 1 describes equation $(4)$ in the $\left(b_{t+1}, b_{t}\right)$ plane. We call this curve $\Phi$ curve. Equation (4) has two stationary solutions. One of them is the origin, and the other equilibrium lies at the intersection of the 45 degree line with the phase line of equation (4), $\Phi$ curve. Figure 1 (i) is called the Samuelson case and Figure 1 (ii) is called the classical case.

Let us run a primary budget deficit $q_{0}=b_{0}>0$ per capita at the beginning of time and preserve primary budget balance $\left(q_{t}=0\right)$ thereafter. How big can initial debt be? Figure 1 (i) shows that in the Samuelson case $b_{0}$ cannot exceed $s(n)$, the golden rule stock of per capita public debt, which is associated with point A. Figure 1 (ii) shows that in the classical case $b_{0}$ cannot exceed zero. Hence, the largest amount of per capita public debt that is consistent with competitive equilibrium $b^{*}$ is either zero or $s(n)$, whichever is greater. $b^{*}=\operatorname{Max}[0, s(n)]$. As shown in Azariadis (1993), when the primary deficit $q$ increases, $b^{*}$ will be reduced.

If $b_{0}>s(n)$, the interest rate needed to induce households voluntary to hold $b_{0}$ would exceed the growth rate $n$ in each period. National debt would grow faster than the economy, with debt service surpassing in finite time the maximal flow of saving which the household sector is capable of. The government debt will not be held by the household any more and the government goes bankrupt. 


\subsection{Example}

Identical households have the following utility function

$$
u=c_{1}^{i} c_{2}^{i}
$$

where $c_{1}^{i}$ is the first-period consumption of generation $i$ and $c_{2}^{i}$ is the second period consumption of generation $i$. Endowment vector is $\left(e_{1}, e_{2}\right)$, where the second-period endowment $e_{2}$ is smaller than the first-period endowment $e_{1}$.

Fiscal policy is $\left(g, \tau_{1}, \tau_{2}\right)$, where $g$ is per capita government spending, $\tau_{1}$ is lump sum taxes levied in the younger period, and $\tau_{2}$ is lump sum taxes levied in the older period. Assuming for simplicity that the primary deficit $q$ is zero, the government budget constraint is given by

$$
\tau_{1}+\tau_{2}=g
$$

Or

$$
b_{2}=\left(1+r_{2}\right) b_{1}
$$

It is assumed that $\tau_{1}<e_{1}, g<e_{2}$; and beginning-of-time national debt $b_{0}$ is zero.

The lifetime budget constraint of the representative household is

$$
c_{1}^{i}+\frac{c_{2}^{i}}{1+r_{2}}=e_{1}-\tau_{1}+\frac{e_{2}-\tau_{2}}{1+r_{2}}
$$

which implies a savings function of the form

$$
s_{1}=e_{1}-\tau_{1}-c_{1}^{i}=\frac{1}{2}\left[e_{1}-\tau_{1}+\frac{e_{2}-\tau_{2}}{1+r_{2}}\right]
$$

Considering (7), the equilibrium sequence of national debt must then satisfy the equation

$$
2 b_{1}=e_{1}-\tau_{1}-\frac{\left(e_{2}-\tau_{2}\right) b_{1}}{b_{2}}
$$

Stationary solutions are $b=0$ at $1+r=\frac{\left(e_{2}-\tau_{2}\right)}{\left(e_{1}-\tau_{1}\right)}$ and $b=\frac{\left[e_{1}-\tau_{1}-\left(e_{2}-\tau_{2}\right)\right]}{2}$ at $r=0$ The latter 
is an asymptotically unstable equilibrium if $e_{1}-\tau_{1}>e_{2}-\tau_{2}$

The largest sustainable value of public debt $b^{*}$ is hence given by

$$
b^{*}=\operatorname{Max}\left[0, \frac{e_{1}-\tau_{1}-\left(e_{2}-\tau_{2}\right)}{2}\right]
$$

Equation (11) implies that $b^{*}$ is increasing with the first-period disposable income $\left(e_{1}-\tau_{1}\right)$ and is decreasing with the second-period disposable income $\left(e_{2}-\tau_{2}\right)$. An increase in $\tau_{1}$ with a decrease in $\tau_{2}$ means an intergenerational transfer from young to old. Thus, from (11) we can say that the higher the intergenerational transfer from young to old, the smaller the amount of $b^{*}$.

Given public consumption $g$ per capita, the largest sustainable value of public debt per capita is attained if $\tau_{1}$ is as small as possible, that is, at $\tau_{1}=0, \tau_{2}=g$. Then, the largest amount of per capita deficit is

$$
b^{*}=\frac{e_{1}-e_{2}+g}{2}
$$

which is positive when $e_{1}+g>e_{2}$.

\subsection{Sustainability and Policy Implication}

As shown in sections 2.1 and 2.2, the higher the primary surplus, the propensity to save, the growth rate, or the intergenerational transfer from old to young, the more likely the sustainability problem will be alleviated. Put differently, any of decreasing growth and saving or increasing public spending and intergenerational transfer payments would contribute to an increase in the primary deficit, resulting to a higher pressure on the sustainability problem.

As explained in Ihori and Sato (2002), fiscal deficits in 1980s have been reduced and its main reasons were to cut public spending to a great extent in the first half of 1980s and to collect taxes in the second half of 1980s. In 1990s we have experienced a rapid increase in fiscal deficits. In 2000s we have seen that an increase in transfer payments (a decrease in net tax revenues) due to aging contributes to higher primary deficits. It is very important to restrain the increasing trend in transfer payments.

There have been a few analyses on the sustainability problem in the government debt in 
Japan. So long as we use the data until 1990, it seems that the government debt has been sustainable in Japan. However, as explained in Ihori and Sato (2002) among others, deficits have increased rapidly since 1990 . We are not sure if the present fiscal system in Japan may be sustainable in the long run.

Ihori, Nakazato, and Kawade (2002) attempted a standard approach to test the fiscal sustainability condition, using the methodology of Hamilton and Flavin (1986). They conducted the empirical analysis for the Japanese fiscal data from 1957 to 1999. To conduct the test, the values for the nominal growth rate, $n$, and the nominal interest rate, $r$, must be specified. Their strategy was to set various values for $r-n$ and to check whether the results are sensitive to the values chosen. The estimated results imply that the null hypothesis cannot be rejected at a $5 \%$ significance level, suggesting that government solvency was not a serious problem until FY 1996. On the contrary, the result for the period 1957-1997 rejects the null hypothesis when $r-n$ is above 0.05, and the results for the period 1957-1998 and the period 1957-1999 also reject the null hypothesis when $r-n$ is above 0.04 .

Bohn (1998) showed that the positive response of the primary surplus to changes in debt in the U. S. suggests that U. S. fiscal policy is satisfying an intertemporal budget constraint. Japan has two serious points in terms of Bohn's theoretical framework. First, the Japanese primary surplus is apparently a decreasing function of the debt-GDP ration since 1990 and hence it does not satisfy Bohn's test. See Figure 2. Doi and Ihori (2003) showed that Japanese government debt does not satisfy a transversality condition for FY 1965-2000.

These observations indicate that fiscal sustainability is a serious issue in Japan. The longer the sample period, the more likely we face the fiscal crisis. First, the Japanese primary surplus is apparently a decreasing function of the debt-GDP ratio since 1990 and hence it does not satisfy Bohn's test. Second, the rate of interest is greater than the growth rate in Japan in the 1990s. It follows that further fiscal expansion of social security will cause the public debt crisis to occur in the near future.

Japan has two serious difficulties in terms of sustainability. It is important to reduce the government deficit in the near future. 


\subsection{Path to fiscal consolidation}

Japan must now move quickly to put its fiscal house in order. Government bonds now sell at low interest despite the huge fiscal deficit. This means that investors are optimistic about the future of Japan's fiscal system. They consider a collapse of public finance unlikely. Such investor confidence reflects the fact the overall tax burden as a percentage of national income remains relatively low. Investors therefore believe that Japanese economy can withstand further tax increases as is stressed by Broda and Weinstein (2004).

However, if the expansionary trend in government spending continues at this pace, the fiscal deficit will inflate further and the ability to raise taxes in the future will be politically limited. Investors will lose confidence in Japan's public bonds if they believe that the nation's public finance is bound for long-term crisis. The result is that interest rates will rise and fiscal failure will become a more tangible reality.

Another concern, assuming that the financial system will be sustained, is what happens if a considerable deficit accumulates over an extended period of time. Public finance will not collapse even if the debt load grows, unless the ratio of debt to GDP also increases. But if that debt ratio rises, it would have a more restrictive impact upon private investment. Public borrowing - the fiscal deficit - would cut into private-sector savings and private investment would be restricted by that much. If the money raised by borrowing is squandered on public works projects, private investment would be restricted even more. Japan's long-term economic prospects would dim even more if growth is restricted, even if the deficit is sustainable and a fiscal collapse is averted.

It is thus useful to promote fiscal reconstruction in two ways. The first is by revamping the fiscal system drastically. These changes are needed.

(1) Introduction of taxpayer-identification numbering system and other useful measures to correct horizontal inequalities in the tax burden

(2) Overhauling the project evaluation system to eliminate wasteful public works programs

(3) Streamlining the revenue-sharing system (the so-called local allocation tax) that is creating "moral hazards" on the part of local governments

(4) Streamlining the "pay as you go" pension and health insurance system that now taps contributions by the young to pay the elderly and thus is spreading a sense of mistrust among young contributors. 
At the current Koizumi administration, seeking to enhance both efficiency and transparency, the efforts to reduce costs and to utilize cost-benefit analysis have been complemented by a new re-assessment system. These changes are desirable but the speed of structural reform is not so high. Confidence in future fiscal management should be enhanced by implementing these and other structural reforms intensively in the next three years or so. Further determined efforts are needed to reform public spending and taxation in a more efficient way. It should be noted that a successful outcome of fiscal reconstruction may increase overall political support for the drastic fiscal reforms.

The other way to promote fiscal reform is to reduce the massive deficit. Needless to say, it is not rational to give top priority to deficit reduction alone. Even so, deficit reduction is still an important policy objective, given the nation's deteriorating fiscal health. The question is how long it should take to cut the deficit. Considering the problems that could arise from delays, a reduction program should be implemented as soon as possible, just as reform of the system. We now consider the long-run macroeconomic effects of deficit reduction, using a computational overlapping generations model.

\section{The Model}

In the following simulation section, the model employs a multi-period overlapping generations model developed by Auerbach and Kotlikoff (1983). Taxes, a public pension scheme, and a public health insurance scheme are also incorporated into the basic model, in order to reflect the existing Japanese system. An economy of the model consists of the household, the firm, and the government sector, where there is only one good considered for simplicity.

The household is assumed to optimize its intertemporal consumption through its lifetime, taking the wage rate, the interest rate, and its own survival rates as given. The tax system, the public pension scheme, and the public health insurance scheme are also assumed to be taken as given by the household. The household is assumed to obtain its wage by supplying its labor inelastically until it retires, and once it retires it never returns to the labor market. There are no altruistic bequest motives and Ricardian equivalence does not hold.

The firm is assumed to maximize its profit, taking the wage rate and the interest rate as given. The wage rate and the interest rate are determined in each factor market with their 
equilibrium condition.

The government sector is assumed to collect taxes from the household, and also to issue government bonds in order to finance its consumption and its transfers to a social security system. The government sector is also assumed to run a pay-as-you-go public pension scheme and a public health insurance scheme. The government is also assumed to accumulate a public pension fund out of the contribution collected from working generations. This assumption reflects the existing Japanese public pension scheme.

It is assumed that there is no private life insurance, and thus there is no mechanism for the household to hedge its risk in terms of a possibility to die in each period. Since the household is assumed to have no bequest motives, this assumption implies that the household leaves an accidental bequest in each period when it dies. However, it is also assumed that there is no uncertainty in the whole economy in terms of an population of each generation, and thus there is no uncertainty in the total (aggregate) amount of bequests inherited in each period.

\subsection{The Household}

The household appears in the economy at age 20 as a decision maker. Although the household faces uncertainty to die in each period, it dies with certainty at the end of 99 years old if it keeps surviving until 99 years old. Denoting the conditional survival rate of $j+20$-age-old generation to age $j+21$ by $q_{i, j+1, j}$, the unconditional survival rate to age $s+20$ of generation $i$ is given by

$$
Q_{i, s}=\prod_{j=1}^{s+1} q_{i, j+1, j}
$$

The survival risk is assumed to be idiosyncratic, and there is no uncertainty in the aggregate population in each period. Each $q_{i, j+1, j}$ is calculated from the life table in Population Projections for Japan:2001-2050 by the National Institute of Population and Social Security Research.

The household is assumed to maximize its expected lifetime utility with respect to its own 
consumption. The household's expected lifetime utility of generation $i$ is given by ${ }^{(4)}$

$$
E\left[V_{i}\right]=\sum_{s=0}^{79} Q_{i, s}(1+\delta)^{-s} U\left(c_{i, s} ; m_{i, s}\right)
$$

where $c_{i, s}$ is consumption at age $s$, and $\delta$ is the time discount rate. $U\left(c_{i, s} ; m_{i, s}\right)$, the instantaneous utility function, is assumed to be CRRA type such that

$$
U\left(c_{i, s} ; m_{i, s}\right)=\frac{\left(c_{i, s}-m_{i, s}\right)^{1-\rho}}{1-\rho}
$$

where $\rho$ is the index of relative risk aversion. $m_{i, s}$ represents a subsistence level of consumption at age $s$, and it is the minimum level of consumption at which the household can be "healthy" in the sense that it can only enjoy its consumption over $m_{i, s}$. The net amount of consumption over $m_{i, s}$ only gives utility to the household. Consumption of medical services is not considered explicitly in this paper, but $m_{i, s}$ can be interpreted as the amount of medical expenditure measured in consumption goods to be spent in order for the household to be healthy at each age $^{(5)}$. Note also that the household only chooses its consumption, taking $m_{i, s}$ as given, but $m_{i, s}$ differs according to its age by reflecting the fact that it would be more expensive to be healthy as aged.

The budget constraint of the $s$-year-old household of generation $i$ at time $t$ is given by

$$
\begin{aligned}
a_{i, s+1}= & {\left[1+\left(1-\tau_{r, t}\right) r_{t}\right] a_{i, s}+\left(1-\tau_{y, t}-\tau_{p, t}\right) w_{t} e_{i, s}+b_{i, s} } \\
& +p s_{i, s}+\left(1-c p_{i, s}\right) m_{i, s}-\left(1+\tau_{c, t}\right) c_{i, s}
\end{aligned}
$$

where $a_{i, s}$ denotes the initial level of its assets of generation $i$ at period $t, r_{t}$ denotes the interest

\footnotetext{
${ }^{(4)}$ According to the result by Hayashi (1995), bequest motives are not considered in this paper. Strategic bequest motives (Bernheim et al. 1985) are also not considered. Since there is no uncertainty in wage income in this paper, a precautionary saving motive for uncertain wage fluctuation is not considered, which was discussed in Horioka and Watanabe (1997).

${ }^{(5)}$ Some studies consider the direct incorporation of the amount of medical services or of the health stock into utility as a control variable in the OLG models (Johansson 2000, Bednarek and Pecchenino 2002). In this paper, however, as expressed in (12), the amount of medical expenditure has simply been introduced as an exogenous variable in order to avoid to have simulation resutls misleadingly, since it seems that there has been no consensus yet in the literature regarding the functional form of utility or the values of key parameters. Although a considerable number of empirical studies have been made on "price elasticity" (e.g., Manning et al. 1987), and relationships between aggregate medical expenditure and GDP (e.g., Gerdtham and Lothgren 2000), the simpliest assumption on the treatment of medical expenditure in the utility function has been made in this paper, particularly in order to rule out ad hoc results in the simulation analysis.
} 
rate, and $e_{i, s}$ denotes the measure of effective labor. Effective labor differs according to $s$, its age, which is equal to $t-i^{(6)}$. The household supplies labor inelastically for simplicity. $w_{t}$ is the wage rate per efficiency unit of labor, and $w_{t} e_{i, s}$ is pre-tax labor income. All taxes considered in this paper are proportional. $\tau_{y, t}, \tau_{r, t}$, and $\tau_{c, t}$ denote the wage income tax rate, the interest income tax rate, and the consumption tax rate, respectively. The contribution rate to a social security system is denoted by $\tau_{p, t}$. The social security system consists of a public pension scheme as well as a public medical health scheme, and the total contribution collected is divided into the two schemes. $p s_{i, s}$ and $\left(1-c p_{i, s}\right) m_{i, s}$ represent public pension benefits and public medical insurance benefits, respectively.

The values of both benefits in the simulation are given based on calculated data from actual data. $c p_{s, t}$ is the self-payment rate of the public health insurance, and the value of it in the simulation is set in order to reflect real aspects. An ex-post moral hazard problem of medical insurance is not considered in this paper explicitly. Denoting the age when the household starts obtaining pension benefits by $R$, and the replacement rate by $\beta_{p}$, the amount of pension benefits is given by

$$
p s_{i, s}=\left\{\begin{array}{ll}
\beta_{p} H_{t} & \text { if } t-i \geq R \\
0 & \text { if } t-i<R
\end{array},\right.
$$

where $H_{t}$, the annual amount of standard compensation, is given by

$$
H_{t}=\frac{1}{R} \sum_{s=0}^{R-1} w_{t} e_{i, s}
$$

where $R+20$ denotes the household's retirement age. It is assumed that the household contributes to a public pension scheme from age 20 to age 64 . It is assumed that there is no private pension market $^{(7)}$.

The amount of medical expenditure measured in consumption goods, represented by $m_{i, s}$, depends on age $s$ and period $t$, and it is given exogenously in this paper. As pointed out by several papers (e.g., Reinhardt 2000), the amount of real per capita health expenditure plotted

\footnotetext{
${ }^{(6)}$ The profile of effective labor follows Kato (2002a).

${ }^{(7)}$ See Iwamoto et al. $(1991,1993)$ or Friedman and Warshawsky $(1988,1990)$ formodels which include the private pension market.
} 
by age shows a U-shaped pattern, and $m_{i, s}$ is assumed to be U-shaped in this paper. Thus, the total amount of public medical insurance benefits increases as an economy becomes aged. As assumed in (13), the public medical insurance benefits to keep the household healthy is given in the form of money in this paper.

The total amount of savings of the household which dies is left as an accidental bequest, and the accidental bequest is assumed to be redistributed to the household which survives in period $t$, which is denoted by $b_{i, s}$. It is assumed through this paper that the household in all generations which survives obtains the equal amount of the accidental bequest in each period ${ }^{(8)}$.

The first order necessary conditions yield the Euler equation such that

$$
U^{\prime}\left(c_{i, s} ; m_{i, s}\right)=q_{i, s+1, s} \frac{1+\left(1-\tau_{r, t+1}\right) r_{t+1}}{1+\delta} \frac{1+\tau_{c, t}}{1+\tau_{c, t+1}} U^{\prime}\left(c_{i, s+1}\right)
$$

from which the optimal consumption path can be derived once the initial value of the household's consumption is given.

Note that the liquidity constraint is not taken into account in this paper. Thus, the household can borrow when it is relatively young. As will be studied later, a decrease in its disposal wage income due to an increase in the contributions to the social security scheme makes the household have negative savings at its relatively early lifetime stage. In reality there are several opportunities to borrow money, and the liquidity constraint is not taken into account in this paper.

\subsection{The Firm}

The firm is assumed to maximize its profit, taking the wage rate and the interest rate as given. The wage rate and the interest rate are determined in the perfectly competitive factor markets with the equilibrium conditions. The aggregate private production function is assumed to be Cobb-Douglas such that

$$
Y_{t}=A_{\text {proc }, t} L_{t}^{\alpha} K_{t}^{1-\alpha}
$$

\footnotetext{
${ }^{(8)}$ Kato (2002a) assumed that only the generation of age 65 in each period received bequests. Atoda and Kato (1993) discussed the timing of receiving bequests.
} 
where $Y_{t}$ represents aggregate output at time $t, K_{t}$ the aggregate private capital stock, $L_{t}$ aggregate labor supply measured by effective labor unit. $A_{\text {proc }, t}$ represents technology of production of the private sector. Assuming that each factor market is perfectly competitive with the above aggregate production function, output is fully distributed to labor and capital. The first order necessary conditions yield

$$
\begin{aligned}
& w_{t}=\alpha A_{\text {proc }, t} L_{t}^{\alpha-1} K_{t}^{1-\alpha} \\
& r_{t}=(1-\alpha) A_{\text {proc }, t} L_{t}^{\alpha} K_{t}^{-\alpha}-\delta_{k},
\end{aligned}
$$

where $\delta_{k}$ denotes the depreciation rate for the capital stock. Substituting (17a) and (17b) into (16) yields

$$
\begin{aligned}
w_{t} & =\alpha \frac{Y}{t}_{t} \\
r_{t} & =(1-\alpha) \frac{Y_{t}}{K_{t}}-\delta_{k}
\end{aligned}
$$

\subsection{The Government Sector}

The government sector consists of a general account and a social security account.

Expenditure of the general account includes general government expenditure and transfers to a public pension account. The expenditure of the general account is financed by taxation and issuing government bonds. The general government expenditure includes government consumption, government investment, interest payment incurred by government debts, and transfers to the household. Note that these transfers to the household is different from the transfers to the public pension account.

The social security account consists of a public pension account and a public health insurance account. The amount of transfers to the public pension account from the general account is characterized by $\eta_{t}$, which is the ratio of the amount of transfers to the total amount of social security benefits. The government sector is assumed to have no particular objective function which it maximizes. 
The budget constraint of the general account is

$$
\begin{aligned}
G E_{t} & =G R_{t}+T G_{-} B O N D_{t}-\left(1+r_{t}\right) B O N D_{t-1} \\
C G_{t} & =r_{C G, t} \cdot Y \\
I G_{t} & =G E_{t}-\left(C G_{t}+\eta_{t} B_{t}\right) \\
G R_{t} & =\tau_{c, t} C_{t}+\tau_{y, t} w L_{t}+\tau_{r, t} r_{t} K_{t}+\tau_{h, t} B Q_{t}
\end{aligned}
$$

where $B O N D_{t}, G R_{t}$, and $G E_{t}$ denote the amount of outstanding government bonds, the total tax revenue, and the total general government expenditure, respectively. TG_BOND $D_{t}$ is the target level of outstanding governmental bonds. Transfers to the public pension account are denoted by $\eta_{t} B_{t}$, where $B_{t}$ is the total social security benefits. $\tau_{r, t}, \tau_{y, t}, \tau_{c, t}$, and $\tau_{h, t}$ denote the capital income tax rate, the labor income tax rate, the consumption tax rate, and the inheritance tax rate, respectively. In the following simulations only the consumption tax rate is endogenously determined to finance the future government policy, and all other tax rates are exogenously fixed at the 2002 values even after 2002. $C G_{t}$ denotes government consumption. The amount of bequests is represented by $B Q_{t}$, and $K_{t}$ is the private capital stock.

The social security account consists of the public pension account and the public health insurance account. The budget constraint of the social security account and the contribution rate are defined as

$$
\begin{aligned}
F_{t+1}^{*} & =\left(1+r_{t}\right) F_{t}+P_{t}-\left(1-\eta_{t}\right) B_{t} \\
\tau_{p, t} & =\frac{F_{t+1}^{*}-\left(1-\eta_{t}\right) B_{t}-\left(1+r_{t}\right) F_{t}}{w_{t} L_{t}},
\end{aligned}
$$

where $F_{t}$ is an accumulated public pension fund at the end of period $t . B_{t}$ and $P_{t}$ denote the total amount of benefits and the total amount of the contributions. The total amount of benefits includes the public pension benefits and the public medical insurance benefits. The contribution rate is determined endogenously in order to satisfy (20) with the target level of the public pension fund, $F_{t+1}^{*}$, which is given exogenously in each scenario. 


\subsection{Market Equilibrium}

The equilibrium condition of the capital market in period $t$ is that the total amount of savings of the household $\left(A_{t}\right)$ plus the total amount of the public pension fund $\left(F_{t}\right)$ are equal to the private capital stock plus the total amount of outstanding government bonds such that

$$
A_{t}+F_{t}=K_{t}+B O N D_{t}
$$

The equilibrium condition of the goods market is that aggregate output is equal to the sum of private consumption $\left(C_{t}\right)$, private investment $\left(K_{t+1}-\left(1-\delta_{k}\right) K_{t}\right)$ and government expenditure $\left(G E_{t}\right)$, which is

$$
Y_{t}=C_{t}+\left(K_{t+1}-\left(1-\delta_{k}\right) K_{t}\right)+G E_{t}
$$

\section{Data and Assumptions}

The purpose of this paper is to examine the long-run macroeconomic effects of future demographic change and the government debt policy numerically, particularly by taking into account the existing public pension scheme and national medical expenditure through the existing public health insurance.

In this paper, in order to make our simulation analysis as close to real circumstances as possible, obtainable actual as well as forecasted data has been used with estimated values of relevant parameters from the empirical research. The key elements relevant to this simulation are the following five aspects; demography, government deficits policy, a public pension scheme, a medical health insurance scheme, and taxes.

\subsection{Demography}

Actual data has been used from 1965 to 2000. Before 1965 population data was calculated backward from the 1965 population data under the assumption that the fertility rate and the mortality rate are the same as those of 1965. Regarding the future population data, the latest version of Projection of Future Population in Japan (Shourai-Jinko-Suikei 2002) has been used in our simulation. Life table (Kanzen-Seimeihyo) and Shourai-Jinko-Suikei 2002 were used 
for obtaining survival rates. Since Projection of Future Population in Japan (Shourai-JinkoSuikei 2002) gives estimates of the future population only until 2100, it has been assumed in our simulation that the number of births and deaths, and the survival rates after 2100 are fixed at the same levels as those in 2100. Figure 3 shows demographic changes based on 3 different scenarios in Projection of Future Population in Japan (Shourai-Jinko-Suikei 2002). In our benchmark simulation its medium variant estimation has been used.

\subsection{Government Deficits}

Until 2002 actual data from SNA has been used in our simulations. From 2003 the future government debts has been given based on the following assumptions: the growth rate of outstanding governments debts keeps decreasing by $0.5 \%$ from $6.57 \%$, the actual growth rate of the ratio of outstanding government debts to GDP in 2002, until 2013. From 2014 the growth rate keeps decreasing but by $0.1 \%$ until 2023. Then the ratio of outstanding governments debts to GDP (the GDP ratio) has been assumed to be constant from 2024. Under these assumptions the ratio converges to a new steady state level, which is $176 \%$ in the benchmark case as shown in Table 1. Note that the actual gross level of the GDP ratio in 2002 is $114.30 \%$. Other 2 more cases regarding the GDP ratios will be discussed later.

\subsection{Social Security System}

The social security system in this paper consists of two schemes; the public pension scheme and the public health insurance scheme.

The actual data has been used until 2002 for both the public pension scheme and the public health insurance. In terms of the contribution rate, the actual data has also been used until 2002. From 2003, the total amount contributed to the social security has been assumed to be used to finance both schemes. In the actual system the public pension contribution (the long term contribution) and the public health insurance contribution( the short term contribution) are typically collected together as the social insurance contribution. The contribution rate has

been assumed in order to satisfy (20), where the target level of the pension fund is exogenously given.

$\beta_{p}$, the replacement rate, was calculated from SNA, and the actual values have been given 
until 2002. From 2003 the ratio has been assumed to be fixed at the same rate of that in 2002, which is $54 \%$.

An aging population affects the endogenous determination of the contribution rate through two channels: One is through the pay-as-you-go public pension scheme. The amount of per capita benefits is determined with (14) and (15), and if the current scheme does not change in the future, then an aging population should increase the contribution rate in order to maintain the same amount of per capita benefits in the future. Another channel is through the public health insurance. $m_{i, s}$, medical expenditure, has been assumed to be U-shaped in this paper. Thus, even though the shape, thus a medical expenditure pattern, will not change in the future, an aging population increases medical expenditure through an increase in the relative number of an aged population, which is more expensive than other populations. Figure 4 shows actual and simulated data of social security burden (GDP) ratios

\subsubsection{Public Pension Scheme}

The public pension scheme has been assumed to be maintained at the same level as that of 2002 in a benchmark case in a sense that it provides the same amount of per capita benefits in the future. The actual data has been used in our simulations until 2002. In terms of the amount of a public pension fund, actual data has been used until 2002. From 2003 the amount of the fund has been assumed to be fixed at the same level of that of 2002 in the benchmark case. Furthermore, the effect of the public pension reform of year 2004 has been investigated. The detailed explanation of the reform will be given later. The calculated future contribution rate and public pension benefits are given in Table 1.

\subsubsection{Public Health Insurance}

The actual data has been used until 2002. Based on National Medical Expenditure by Ministry of Health, Labour and Welfare, SNA data was modified. The modification gives per capita public health insurance benefits at each age. Until 2002 the actual per capita benefits at each age were calculated, which show a U shaped profile on age. From 2003 it has been assumed that the U shaped pattern does not change. This implies that $m_{i, s}$ changes with $s$ but not with $i$ from 2003. However, due to an aging population, the ratio of the public health insurance benefits to 
GDP increases gradually as shown in Table 1.

\subsection{Taxes}

Except for a consumption tax, all other taxes (a labor income tax, an interest income tax, and an inheritance tax) have been assumed to be fixed at the 2002 levels even after 2002. The 2002 levels of tax rates were obtained from the actual SNA data. Note that the consumption tax is only the indirect tax in this paper, and its rate has been calculated in order to coincide the calculated total amount of indirect tax revenue with the actual total amount of indirect taxes revenue in SNA. Thus, the consumption tax rate calculated in this paper does not coincide with the actual rate. The total amount of the consumption tax revenue in this paper corresponds to the actual total amount of indirect taxes revenue in SNA. Figure 4 also shows actual and simulated data of tax burden (GDP) ratios.

\subsection{Technological Progress}

Technological progress of private production plays a very important role. As has mentioned, a $1 \%$ difference in an annual rate of technological progress results in a substantial difference in future GDP. Thus, a very careful attention should be paid to the assumption on technological progress.

In this paper technological progress was calculated by the Solow Residual. According to Hayashi and Prescott (2002), 0.361585 was given to a capital coefficient in the estimation. The calculated values of technological progress is given in Figure 5. Average values between 1993 and 2002 and between 1983 and 1992 are $-0.5 \%$ and $0.1 \%$, respectively. Thus, in our benchmark simulations the future value of technological progress from 2003 is assumed to be zero in order to reflect reality of the last two decades. Note that these estimated values were however obtained based on the assumption that public capital did not affect any private production. If we took into account a positive effect of public capital, then these figures might be bigger. Thus, other cases with positive technological progress are also explored as extended cases in Section 5.4 The assumption that zero technological progress also continues in the future as well might be too strong. Section 5.4 investigates the effect of the difference in technological progress in comparison with the zero technological progress, where a $0.5 \%$ and a $1 \%$ increase in annual technological 
progress in private production are assumed to occur. Note that the zero technological progress assumption is maintained until Section 5.4.

The values of parameters have been obtained from existing empirical research ${ }^{(9)}$. The values used in this paper are summarized as follows:

\section{The Values of Parameters}

\begin{tabular}{cccccc}
\hline$\delta$ & $\rho$ & $\alpha$ & $\delta_{k}$ & $\beta_{p}$ & $\eta^{(10)}$ \\
\hline-0.01 & 2.5 & 0.63842 & 0.089 & 0.5 & 0.2776 \\
\hline
\end{tabular}

\section{Simulation Analysis}

\subsection{Benchmark Simulation}

In case of the benchmark simulation, the government deficits has been assumed to converge to a $176 \%$ level in a new steady state. The public pension fund has been assumed to converge to a $42.1 \%$ level. Per capita public pension benefits and per capita medical insurance benefits have been assumed to be fixed at the 2002 level. The consumption tax rate is determined endogenously to satisfy the budget constraint of the general government account, and the contribution rate is determined endogenously to satisfy the budget constraint of the social security account, which consists of the public pension scheme and the public health insurance scheme.

Note that the total amount of the public pension benefits and the total amount of the public health insurance benefits change due to the demographic change even though per capita benefits are fixed at the 2002 level. GDP also changes endogenously, and thus, the ratios to GDP change as shown in Table 1.

Outstanding differences from Broda and Weinstein (2004) can be found in GDP growth rates and in interest rates in Table 1 . They assumed several rate gaps from 0 to $4 \%$ between the interest rate and the GDP growth rate ${ }^{(11)}$. Note that in their paper the GDP growth rates were assumed to be positive. However the GDP growth rate in our paper will be negative from a certain time in the future. Thus, in our paper the rate gaps between the interest rate and the GDP growth rate can be bigger than $4 \%$ as shown in the last column of Table 1.

\footnotetext{
${ }^{(9)}$ See Uemura (2002) for detailed discussions.

${ }^{(11)}$ The rate gap is the interest rate minus the nominal GDP growth rate.
} 
As shown in Table 1,the GDP growth rate becomes negative from 2015 due to two reasons: A rapid decrease in labor force and the zero rate of technological progress. Table 1 also shows the difference between the GDP growth rate and the interest rate in the last column.

Tax burdens will increase near to $36 \%$ in 2050 due to a big gap between the GDP growth rate and the interest rate. The big gap results in high tax burdens to finance interest payments incurred by outstanding governments debts, even though the government tries to make the primary balance positive from 2010. Note that the simulated value in 2002 is slightly higher than the actual value. This is because the primary balance in the benchmark simulation is assumed to be made positive at an earlier stage compared to the actual situation. In the benchmark case it has been assumed that the primary balance will be positive by 2010 , and the difference in the value of the tax burden ratio between the actual one and the simulated one can be explained as the situation that it would be difficult to achieve a positive primary balance by 2010 with the current tax level.

The increasing trend in the ratio of public pension benefits to GDP as well as in the ratio of public health insurance benefits to GDP can be explained by an aging population as has been pointed out by several papers (Takayama and Kitamura (1999), Dekle (2002), Broda and Weinstein (2002)). The social security burden ratio will increase up to $23.27 \%$ in 2050 if the current system is maintained.

The result of the increasing trend in the public health insurance benefits also supports existing empirical research. As has been estimated in empirical research, public health insurance benefits are expected to increase at $1 \%$ every 10 years, and the ratio of public health insurance benefits to GDP will be around $9.6 \%$ in 2050 .

This figure can also be shown in the conventional definition, the national income burden ratio. The national income burden ratio is defined as the ratio to national income, and it will have to be around $80 \%$ in 2050 . Our striking result is that if the government wants to have a positive primary balance by 2010, then the future burden should be very high, implying that the current financial situation facing the Japanese government in terms of governments deficits is very dangerous. If the government postpones the timing to pay its deficits back, then the situation would be worse due to more interest payment incurred by the huge amount of outstanding government debts. If the government targets a $50 \%$ level of the national burden 
ratio, then our result can predict when it reaches. If the future burden is measured in the ratio to national income, then in 2009 the national income burden ratio will become $50.39 \%$. If it is measured in our definition, then the national burden (GDP) ratio will become over $50 \%$ in 2030 .

Due to the big gap between the GDP growth rate and the interest rate, and an aging population, the national burden (GDP) ratio, which is defined by the tax burden (GDP) ratio plus the social security burden (GDP) ratio, will increase to around 59\% in 2050 in this benchmark case.

The result of high burdens in the future can further be described along the model: In terms of distortion by taxation and the public pension scheme, an increase in the contribution rate does not generate distortion in labor supply due to an exogenous assumption of labor supply.

However, an increase in the contribution rate results in a decrease in disposal income. Thus, a rapid increase in the future contribution rate gives more burdens to future generations under the current modified pay-as-you-go public pension scheme, and future generation will be worse off by the increase in the contribution rate.

An increase in the consumption tax rate in the future makes future goods relatively more expensive, and generates distortion in a lifetime consumption path. This also generates distortion in savings, resulting in distortion in the capital market as well. If the increase in the consumption tax rate induces an increase (a decrease) in private savings, then the increase in the consumption tax to finance interest payments incurred by outstanding government debts result in higher (lower) GDP in the future, and thus future generation will be better (worse) off. Furthermore an increase in interest payments incurred by outstanding government debts implies an increase in interest income, and an increase in the consumption tax does necessarily result in a decrease in disposal income.

The increase in the consumption tax and the increase in the contribution rate definitely change a path of lifetime savings, and thus all key parameters such as the interest rate in the capital market. All these effects finally affects future GDP. Furthermore, particularly in the transition to an aging population, a relative difference in the total amount of tax as well as pension burdens exists among different generations. Thus, intergenerational redistribution through the current tax and the public pension scheme should be evaluated based on utility of different generations. This evaluation on utility of different generations has been explored by 
comparing the benchmark case with the following extended cases.

\subsection{Extension}

Simulation results obviously depend on several assumptions, particularly assumption on the future outstanding government debts and the future population structure. In this paper different scenarios have been explored as follows.

\subsubsection{Outstanding Government Debts}

Two different scenarios in terms of future outstanding government debts have been studied. The benchmark case and two different scenarios ("high" and "low") can be shown in Figure6. The "high" debts scenario would correspond to the current situation in a sense that it seems quite difficult to have a positive primary balance soon. In the "high" debts scenario, the primary balance does not become positive until 2022, and thus outstanding government debts ratio in a gross value becomes $450 \%$ in the final steady state. On the other hand, in the "low" debts scenario, outstanding government debts are paid back at a relatively early stage as shown in Figure 6. In the "low" debts scenario, the primary balance becomes positive in 2006, and thus the final level of outstanding government debts ratio in a steady state is $150 \%$. Depending on the timing of the primary balance being positive, the final levels of outstanding government debts ratio in a steady state differ. The effects of the difference in future government debts policies on key parameters are summarized in from Table 2 to Table 6 . In each table, 3rd and 4th columns show the effects of the difference in outstanding government debts policies. 2nd column shows the benchmark case. The comparison of the benchmark case with "high" and "low" debt policies gives results.

Apparently, in the "high" debts policy the future tax burden ratio is higher than the bench-

mark case, and the tax burden ratio will increase over $50 \%$ in the "high" debts policy. In the "low" debts policy, the tax burden ratio is higher than the benchmark case until around 2020, but the lowest tax burden ratio can be achieved eventually.

\section{Welfare Comparison}

Table 7 shows the welfare comparison of two different policies with the benchmark case. 2nd and 3rd columns give results. Note that the year corresponds to the year when a generation 
becomes 20 year old, and for instance year 2002 means the welfare of the generation which becomes 20 year old in year 2002. A positive (negative) number implies that the generation does (does not) prefer the policy to the benchmark case. As Table 7 shows, the "high" debts policy is not preferable for future generations, since the policy postpones the burdens to future generations. On the other hand, the "low" debts policy is not preferable for current generations, since the current generations have to pay the burden by paying relatively high tax.

\subsubsection{Difference in Future Demography}

The latest version of Projection of Future Population in Japan (Shourai-Jinko-Suikei 2002) presents three different scenarios (low, medium and high variant estimations) regarding the future population as shown in Figure 3. In the benchmark simulation the medium variant estimation has been used. Table 2 - 6 show the effect of different future populations on relevant variables. As can be expected, the effect of a difference in the future populations appears in the contribution rate and the social security burden ratio.

\section{Welfare Comparison}

Table 7 shows the effect of the demographic difference on utility. 4th and 5th columns show the comparison with the benchmark case. Since there are less people in the row variant estimation, the contribution rate and thus the social security burden ratio are higher than those in the benchmark case (medium variant estimation). If a future population is lower than the benchmark case, then the demographic difference negatively affects utility as shown in Table 7 .

\subsection{Public Pension Reform}

As can be seen in Table $1-5$, a future increase in the contribution rate as well as in the amount of public pension benefits cannot be avoided due to a rapid aging population if the current system is maintained. In 2004 the public pension scheme was reformed, and the main feature of the reform is to try to maintain the total level of the contribution rate in an aging Japan. In the reform, the following points have been agreed on: In stead of maintaining the amount of future benefits, the amount of future contributions is maintained. Actually the contribution rate will be increased until 2017 in order to finance an increase in the total benefits due to an aging population, but after 2017 the contribution rate is fixed at the 2017 level, and the amount 
of total benefits will be adjusted in order to finance an increasing amount of total benefits. In our simulation the amount of per capita benefits has been assumed to be fixed at the 2002 level in the future, but the total level of benefits increases as Japan becomes aged. In order to investigate the effect of the reform, $\beta_{p}$, the replacement rate, was chosen as a control variable to maintain the future level of the contribution rate. In other words, $\beta_{p}$ was carefully chosen so that the endogenously determined values of the contribution rate follows the actual values designed in the reform. The effect of the reform is given in the last column in from Table 2 to Table 6. The comparison can be given with the second column (base) of each table. For example, the effect of the reform on the social security burden ratio can be explored by comparing the second column with the last column of Table 5. As shown in Table 5, in 2050 the reform will successfully reduce the social security burden ratio from $23.27 \%$ to $15.02 \%$.

\section{Welfare Comparison}

The effect of the reform evaluated in welfare is given in Table 7. The last column gives the comparison with the benchmark case. The benchmark case corresponds to the policy in which the current system is maintained. The 2004 reform tries to reduce the burdens on future generations through the public pension scheme, and its effect is shown in this table. As Table 7 shows, the reform is more preferable by more future generations.

\subsection{Positive Technological Progress ${ }^{(12)}$}

Different assumptions on future technological progress induce different results. Kato (2002d) showed that an introduction of $0.5 \%$ dimishing growth of technological progress for 40 years eventuated in a $8.4 \%$ increase in per capita income in a new steady state, and also that $1.0 \%$ dimishing growth achieved a $18.3 \%$ increase in per capita income.

It has been assumed so far that technological progress in the future is fixed at a zero rate. However, the difference in the assumption of technological progress does matter particularly in terms of the difference in the gap between the interest rate and GDP. Thus, although the zero assumption on technical progress reflects the actual aspect for the last two decades, other two cases with $0.5 \%$ as well as $1.0 \%$ technological progress are worth being investigated in comparison with the zero technological progress case, in order to explore how much different assumptions

\footnotetext{
${ }^{(12)}$ This section has been added to an earlier version based on detailed comments by Robert Dekle, David Weinstein, and Takatoshi Ito. We would like to thank them for their valuable comments.
} 
regarding technological progress change simulation results.

Another assumption is introduced in this section regarding the future growth rate of medical expenditure: The actual data shows that annual growth rates of medical expenditure of all cohorts except a cohort between age 0 and 14 are between $0.7 \%$ and $0.9 \%^{(13)}$, and thus it is assumed in both cases ( $0.5 \%$ and $1 \%$ technological progress cases) that medical expenditure increases at $1 \%$ annually in the future. Furthermore, in order to distinguish the effect of increasing medical expenditure from the effect of technological progress, another case is investigated, where technological progress increases at a $1 \%$ rate with a zero growth rate of medical expenditure.

Table 8 and 9 show the effects of the difference in future technological progress. The comparison of Table 1 with Table 8 and 9 highlights the effects of the difference in technological progress. As shown in Table 8 and 9, the GDP growth rate is higher as technological progress is higher. Compared to the benchmark case with zero technological progress, which is shown in Table 1, the GDP growth rate would not be negative until year 2040 when technological progress increases at $1 \%$ annually, which is intuitively plausible.

A striking result is that the interest rate is higher as technological progress is higher. The equilibrium interest rate is determined in the capital market through the interaction between demand and supply, and this result can be explained with the following four reasons: The first reason is the effect on the demand side. An increase in technological progress shifts the production function upward, resulting in an increase in demand for private capital. This implies an upward shift of the demand curve in the capital market, inducing an increase in the interest rate.

Other three reasons are the effects on the supply side. The second reason is the effect of an expansion of technological progress on income. The increase in income generates a positive income effect, but it does not determine whether or not private savings are stimulated either if goods are normal with the utility function specified in our paper. As long as both current and future consumption are normal goods, the income effect does not determine whether or not private savings increase.

The third reason is the effect on the relative price. Since an increase in the interest rate implies a decrease in the relative price of future consumption, it stimulates private savings

\footnotetext{
${ }^{(13)}$ The annual growth rate of medical expenditure of the cohort between age 0 and 14 is $4.3 \%$.
} 
through the substitution effect.

The fourth reason is related to the third one in a sense that it affects the relative price. An increase in the interest rate results in more interest payments incurred by government debts. This implies an increase in a future consumption tax rate. Since the increase in a future consumption tax rate implies an increase in the relative price of future consumption, the increase in the tax rate results in a decrease in private savings through the substitution effect. Thus, an expansion of future technological progress affects both the supply and the demand sides of the capital market in a complicated way. In particular, the overall effect on the supply side cannot be determined, depending on the above mentioned channels. In our simulations, an expansion of future technological progress results in an increase in the interest rate. Due to the increase in the interest rate, although the expansion of technological progress also induces an increase in the GDP growth rate, the gaps between the interest rate and the GDP growth rate become bigger rather than smaller, as shown in the last column of Table 8 and 9 .

In addition, due to an increase in the equilibrium interest rate, the amount of interest payments incurred by government debts increases, thus eventuating in an increase in future tax burdens, which is shown in 4th column in Table 8 and 9. However, the effect on the social security system is different. There are two effects: On one hand, since $\beta_{p}$, the replacement rate, is assumed to be constant, an increase in future GDP thus future income by an expansion of technological progress results in an increase in the amount of pension benefits after retirement. This effect increases the contribution rate of the social security system. On the other hand, an increase in future GDP also has an effect to reduce the contribution rate, since the contribution rate is determined endogenously based on the ratio of the total amount of the aggregated pension benefits to GDP. Table 8 shows that the former effect is stronger than the latter effect when technological progress grows at $0.5 \%$, but a $1.0 \%$ increase in technological progress is large enough in a sense that future contribution rates can be maintained at lower levels, as shown in Table 9. Our simulation result shows that not only an expansion of future technological progress results in more tax burdens in the future, but also an insufficient expansion of technological progress results in more burdens in the social security system as well.

Table 10 shows the effect of the difference in future medical expenditure. The comparison of Table 9 with Table 10 explores the effect of the difference in future medical expenditure. Lower 
medical expenditure in the future obviously results in the lower contribution rate in the future, resulting in an increase in future disposal income. The increase in the future disposal income weakens an incentive to save for future consumption, and it reduces the amount of aggregated savings. The decrease in the savings results in an increase in the interest rate, as shown in Table 10, and future tax rates must increase to finance more interest payments, although medical expenditure is lower in the future. Thus, as shown in Table 10, future tax burden ratios are relatively higher, even though future contribution rates are lower.

\section{Conclusion}

This paper has examined the effects of the demographic change and the government debt policy in Japan on economic growth and economic welfare, particularly by taking into account the existing public pension scheme as well as national medical expenditure through the existing public health insurance, where a computational overlapping generations model is used within a general equilibrium context.

One of the main results of this paper is that the tax burden (GDP) ratio will increase up to about $36 \%$, and the social security burden (GDP) ratio will increase up to $23.3 \%$ in 2050 , even though the government tries to have a positive primary balance by 2010 .

The national burden ratio to GDP, defined by the sum of the tax burden (GDP) ratio and the social security burden (GDP) ratio, will be around 59\% in 2050 in the benchmark case. This figure can also be shown in the conventional definition, the national income burden ratio. The national income burden ratio is defined as the ratio to national income, and it will have to be around $80 \%$ in 2050 . Our striking result is that if the government wants to have a positive primary balance by 2010 , then the future burden should be very high, implying that the current financial situation facing the Japanese government in terms of governments deficits is very dangerous. If the government postpones the timing to pay its deficits back, then the situation would be worse due to more interest payment incurred by the huge amount of outstanding government debts.

An aging population will result in an increase in the total amount of the public pension benefits as well as the total amount of the public health insurance benefits, even though the amount of per capita benefits are fixed at the 2002 level in the future, if the current scheme is 
maintained. The ratio of public health insurance benefits to GDP is expected to increase at 1 $\%$ every 10 years, and the ratio will be around $9.6 \%$ in 2050. The 2004 public pension reform will successfully result in a 13 point decrease in the contribution rate from $36.44 \%$ to $23.53 \%$, and reduce the social security burden ratio to GDP by 8 points from $23.27 \%$ to $15.02 \%$ in 2050 , compared with the benchmark case.

Another striking result is that future technological progress will increase future tax burdens, although an expansion of technological progress increases future GDP. In our simulation an expansion of future technological progress results in an increase in the future equilibrium interest rate, thus inducing an increase in the future consumption tax rate to finance more interest payments incurred from government deficits. The gaps between the interest rate and the GDP growth rate become bigger rather than smaller as higher technological progress is assumed in the future.

Although our estimation of technological progress based on the actual data of the last two decades without an effect of public capital on private production is quite close to zero, an assumption of positive technological progress in the future seems more appropriate. Our simulation result, particularly regarding the effect of future technological progress, shows that interest payments incurred by the huge amount of government debts will matter in the future due to an increase in the interest rate. The actual interest rate is very low currently, but our simulation result shows that if the future interest rate increases due to an expansion of technological progress, or whatever, then a drastic increase in tax rates cannot be avoided. It is also worth noting that Japan plays an important role in the world economy, implying that the domestic interest rate cannot last to be relatively too low for a long time compared to other interest rates in the global economy. In order to explore this effect, our model should be extended to an open economy model. However, an intuitive inference can be given within our closed economy model: An expansion of the model to incorporate the intersection between Japan and other world economies through the capital market will result in an increase in the Japanese interest rate in simulations, and thus the future fiscal situation facing Japan will be predicted to be more severe than our results of this paper. The difference in prediction of the future fiscal situation in the literature comes from different results regarding the gap between the interest rate and the GDP growth rate. If our simulation results are compared to the actual fiscal situation, our 
results seem too pessimistic and unrealistic. However, if a possibility of an increase in the future interest rate is taken into account, our simulation results can be more realistic rather than too unrealistic. 


\section{References}

[1] Altig, D., A. J. Auerbach, L. J. Kotlikoff, K. A. Smetters, and J. Walliser (2001) "Simulating fundamental tax reform in the United States," American Economic Review 91(3), 574-95.

[2] Atoda, N., and R. R. Kato (1993) "KoureikaShakai ni okeru Chochiku to Zeisei," Tezukayama Daigaku Discussion Paper, No.J-034 [in Japanese]

[3] Auerbach, A. and L. J. Kotlikoff (1983) "An examination of empirical test of social security and savings," in E. Helpman, A. Razin and E. Sadka eds., Social Policy Evaluation: An Economic Perspective, 161-179.

[4] Azariadis, C. (1993) Intertemporal Macroeconomics, Blackwell

[5] Bohn, H. (1998) "The behavior of U.S. public debt and deficits," Quarterly Journal of Economics 113, 949-963.

[6] Broda, C. and D. E. Weinstein (2004) "Happy news from the dismal science: Reassessing Japnese fiscal policy and sustainability," NBER Working Paper 10988.

[7] Dekle, R. (2002) "Population aging in Japan: its impact on future saving, investment, and budget deficits," Department of Economics, USC

[8] Diamond, P. A. (1965) "National debt in a neoclassical growth model," American Economic Review 55, 1125-1150.

[9] Doi, T. and T. Ihori (2003) "Sustainability of government deficits in Japan: Including trends in local government finance," in Noayuki Yoshino, Shigehito Inukai and Nobusuke Tamaki eds., Enhancing Market Functions in Japan, 3-29, Keio University Press

[10] Friedman, B. M., and M. Warshawsky (1988) "Annuity prices and saving behavior in the United States," in Z. Bodie, J. Shoven, and D. Wise eds., Pensions in the U.S. Economy, 53-77, University of Chicago Press

[11] Friedman, B. M., and M. Warshawsky (1990) "The cost of annuities: implications for saving behavior and bequests," Quarterly Journal of Economics 105(1), 135-154.

[12] Hamilton, J. and M. Flavin (1986) "On the limitations of government borrowing: A framework for empirical testing," American Economic Review 76, 808-816.

[13] Hayashi, F. (1995) "Is the Japanese extended family altruistically linked? A test based on Engel curves," Journal of Political Economy 103(2), 661-674.

[14] Hayashi, F. and E. C. Prescott (2002) "The 1990s in Japan: A Lost Decade," Review of Economic Dynamics $\mathbf{5}(\mathbf{1}), 206-235$.

[15] Horioka, C. Y. and W. Watanabe (1997) "Why do people save? A micro-analysis of motives for household saving in Japan," Economic Journal 107(442), 537-552.

[16] Ihori, T. and H. Kondo (1998) "Koukyo toshi to minkan shohi : Zaisei akaji to jousuu no bunseki," Financial Review 47, 106-133. [in Japanese] 
[17] Ihori, T., T. Nakazato, and M. Kawade (2002) "Japan's fiscal policies in the 1990s," The World Economy 26, 325-338.

[18] Ihori, T. and M. Sato eds. (2002) Government Deficit and Fiscal Reform in Japan. Kluwer Academic Publishers.

[19] Iwamoto, Y. (2004) "Issues in Japanese health policy and medical expenditure," in T. Tachibanaki ed., The Economics of Social Security in Japan, 219-232, Edward Elger.

[20] Kato, K. (1967) "Shihon Stock (Kinyu Base) deno Chiiki Kouzou Bunseki," in Y. Takeuchi, Nihon no Shakai Shihon: Genjou Bunseki to Keikaku, 76-100, Kashima Shuppankai. [in Japanese]

[21] Kato, R. R. (1998) "Transition to an aging Japan: Public pension, savings, and capital taxation," Journal of the Japanese and International Economies 12, 204-231.

[22] Kato, R. R. (2000) "Wagakuni no Koureika Ikou to Zaisei Akaji", in Ihori, Kato, Nakano, Doi, Nakazato and Sato, Zaisei Akaji no Keizai Bunseki : Chuchoki Shiten karano Kousatsu, Chap, 3, Zaisei Akaji no Keizai Bunseki Shiten Series 16, Keizai Kikakucho Keizai Kenkyusho, Keizai Kikakucho [in Japanese]

[23] Kato, R. R. (2002a) "Government deficits in an aging Japan," in T. Ihori and M. Sato eds., Government Deficit and Fiscal Reform in Japan, Kluwer Academic Publishers.

[24] Kato, R. R. (2002b) "Government deficit, public investment, and public capital in the transition to an aging Japan," Journal of the Japanese and International Economies 16, 462-491.

[25] Kato, R. R. (2002c) "Koureika Shakainiokeru Zaisei Akaji Koukyo Toushi Shakai Shihon", Ihori,Kato, Nakano, Doi, Nakazato, Kondo and Sato, Zaisei Akaji to Keizai Katsudou : Chuchoki teki Shitenkara no Bunseki, Chap. 1, Keizai Bunseki No.163, Naikakufu Keizai Shakai Sougou Kenkyusho, 7-70. [in Japanese]

[26] Kato, R. R. (2002d) "Government deficit, public investment, and public capital in the transition to an aging Japan (a full version)," Working Paper Series, No. 74, Faculty of Economics, Shiga University.

[27] Kawade, M, S. Bessho, and R. R. Kato (2005) "Public capital and goverment deficits in an aging Japan: Simulation analysis," CRR Working Paper Series, No. A-5, Shiga University.

[28] Keizai Kikakucho Sougou Keikakukyoku (1998) Nihonno Shakai Shihon 21 Seiki eno Stock, Toyo Keizai Shinpousha. [in Japanese]

[29] Reinhardt, U. E. (2000) "Health care for the aging baby boom: Lessons from abroad," Journal of Economic Perspectives 14(2), 71-83.

[30] Samuelson, P. (1958) "An exact consumption-loan model of interest with or without the social contrivance of money," Journal of Political Economy 66, 467-482.

[31] Tokita, T. (2002) "The prospects for reform of the Japanese Healthcare system," Pharmacoeconomics 20(S3), 55-66. 


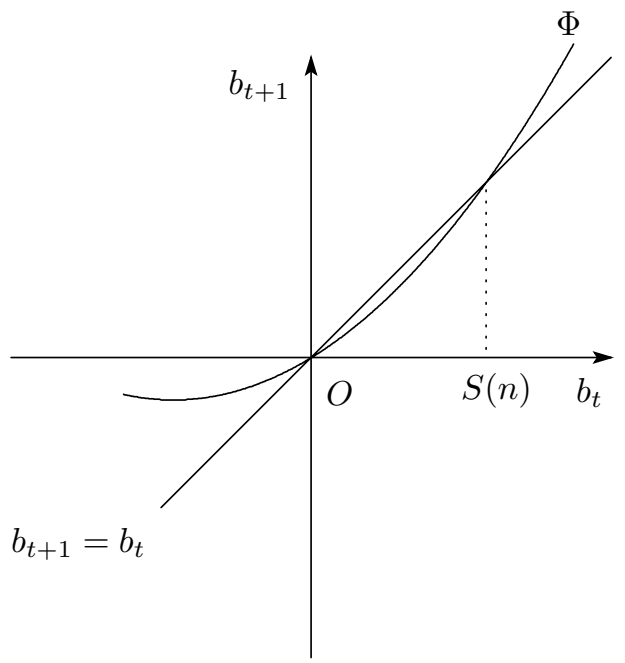

Figure (i):

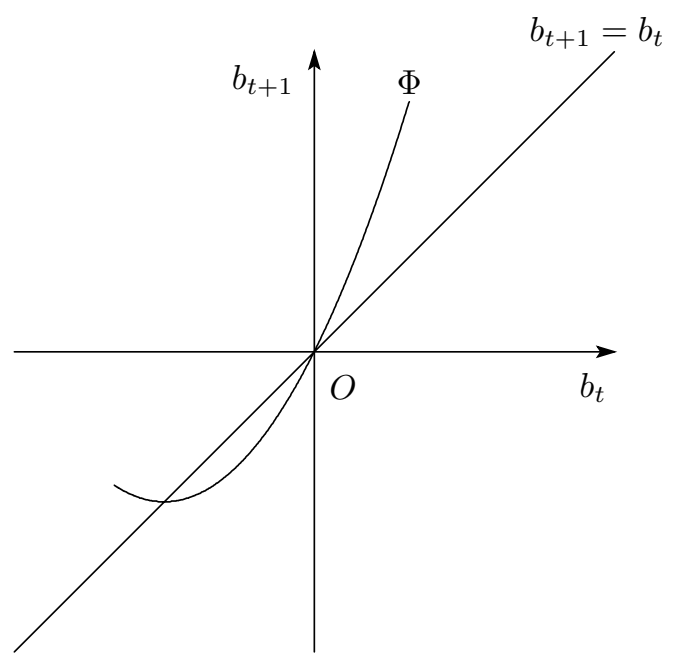

Figure (ii): 
Figure 2

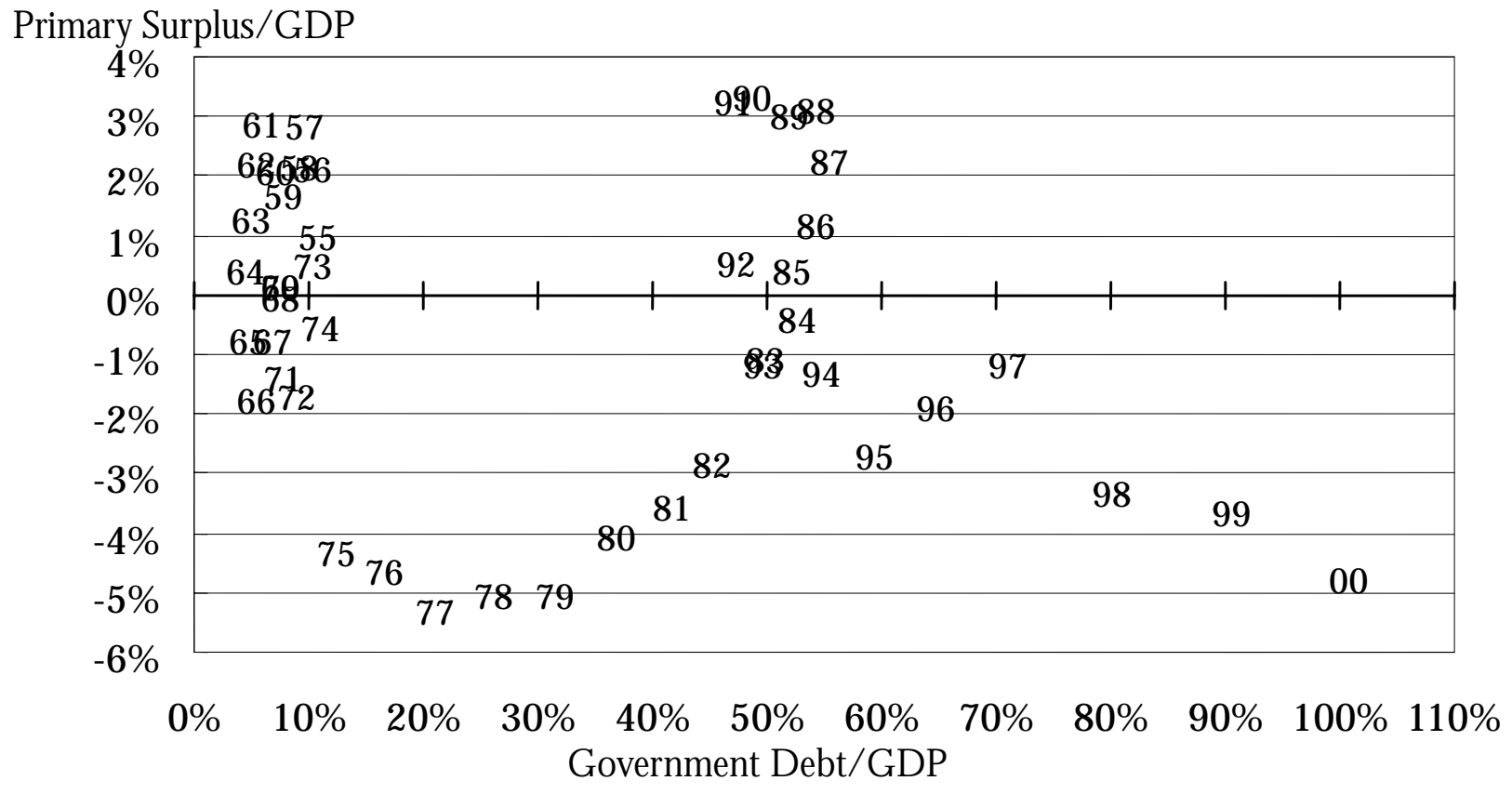


Figure 3: Aging Rates

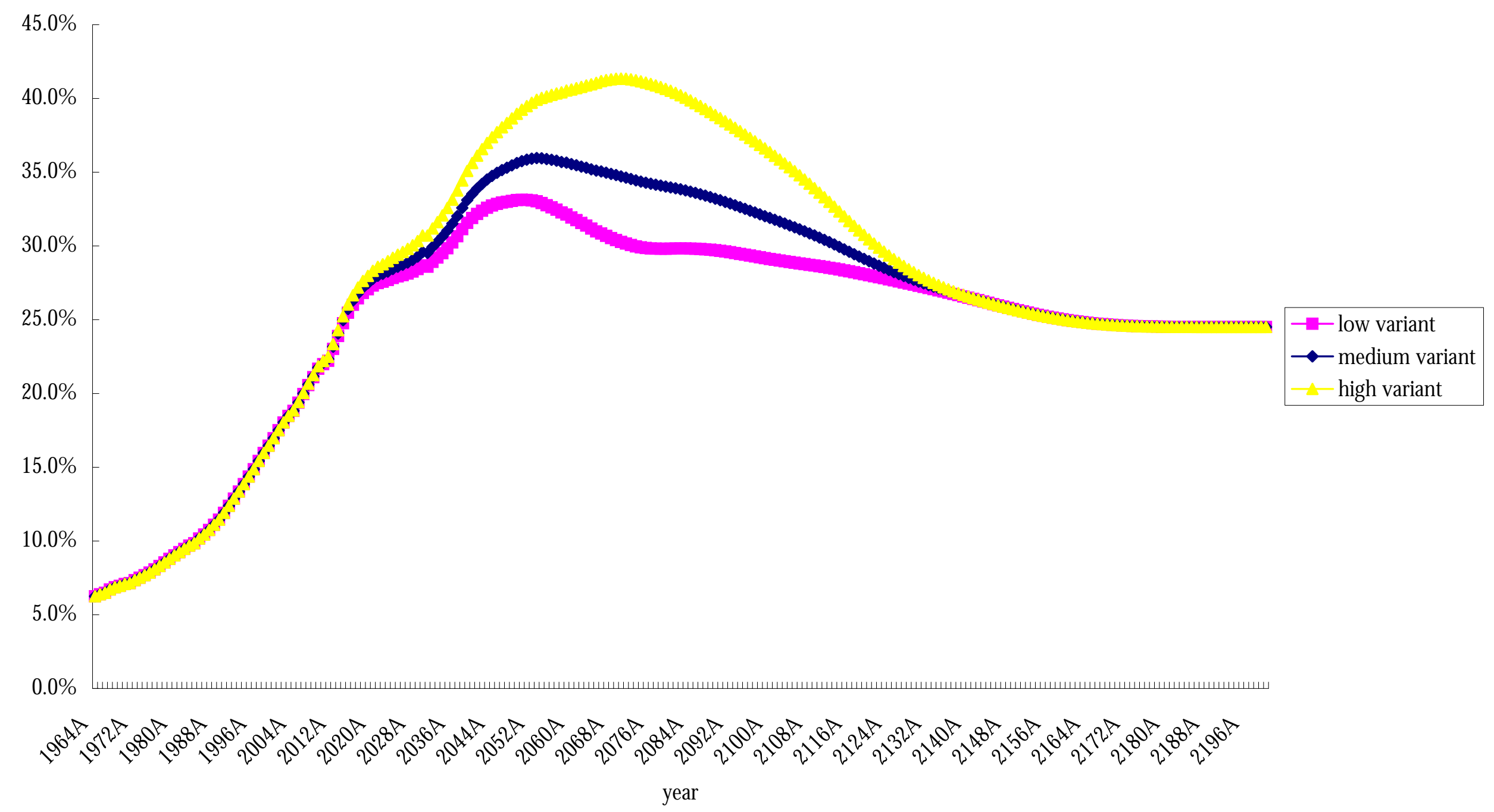


Figure 4: Ratios to GDP

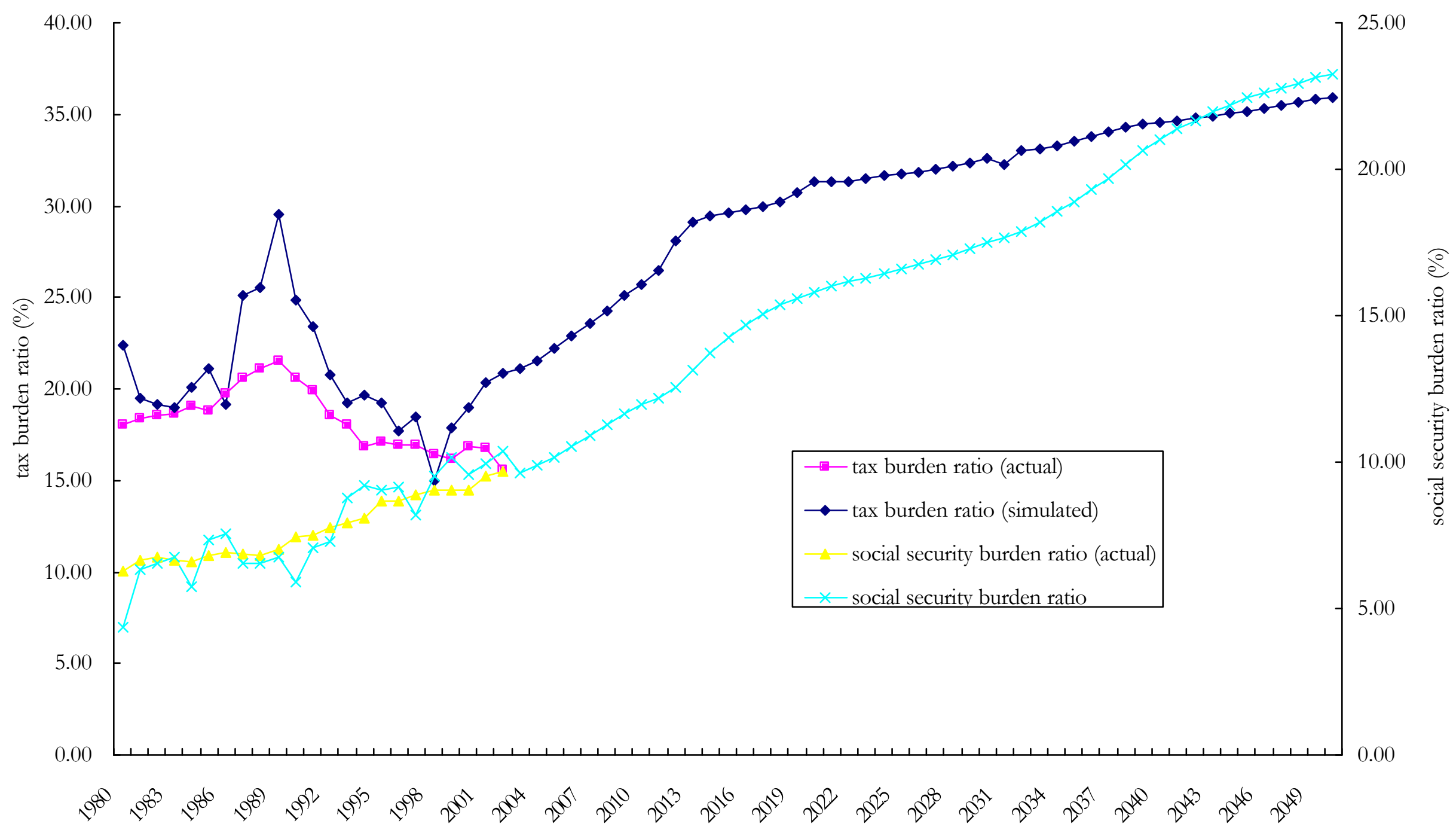


Figure 5

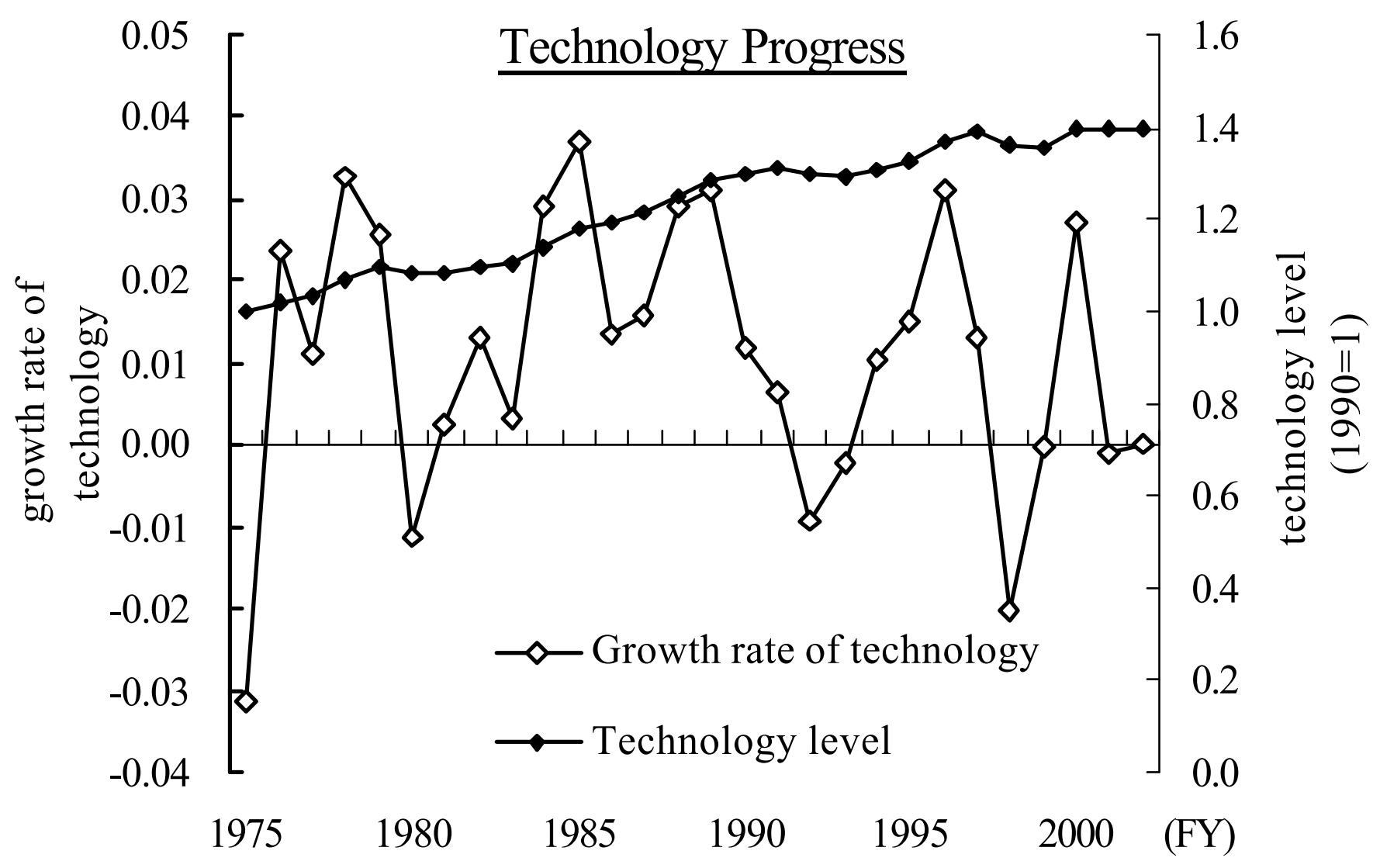


Figure 6: Primary Balance

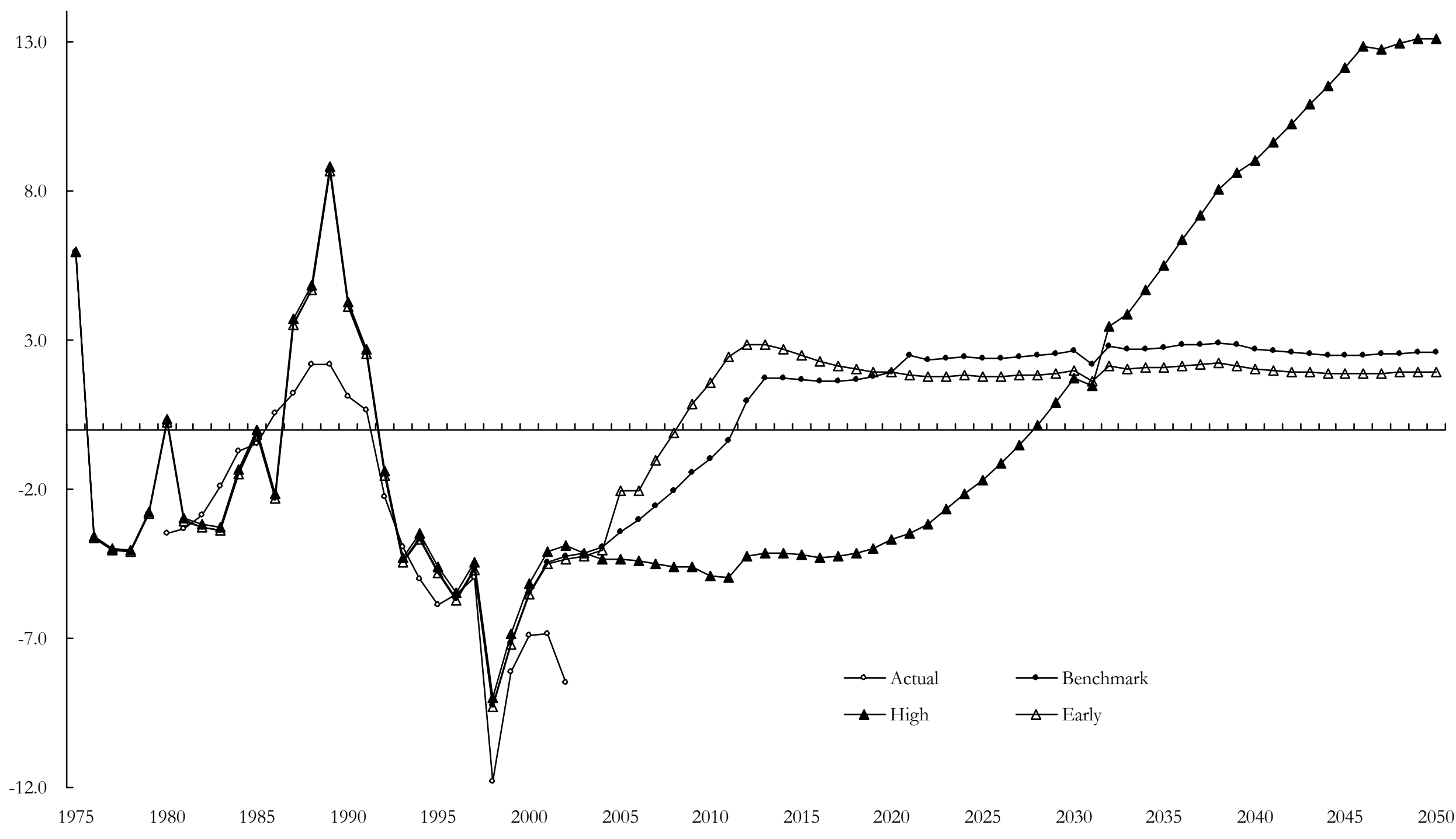


Table 1: Base Simulation Results

\begin{tabular}{|c|c|c|c|c|c|c|c|c|c|c|}
\hline Year & $\begin{array}{c}\text { Bond } \\
\text { Outstanding } \\
(\text { GDP Ratio }) \\
\end{array}$ & $\begin{array}{c}\text { GDP } \\
\text { Growth } \\
\text { Rate }(\%), n\end{array}$ & $\begin{array}{c}\text { Primary } \\
\text { Balance } \\
(\text { GDP Ratio }) \\
\end{array}$ & $\begin{array}{c}\text { Tax } \\
\text { Burden } \\
(\text { GDP Ratio }) \\
\end{array}$ & $\begin{array}{c}\text { Social Security } \\
\text { Burden } \\
(\text { GDP Ratio }) \\
\end{array}$ & $\begin{array}{l}\text { Social Security } \\
\text { Contribution } \\
\text { Rate }(\%)\end{array}$ & $\begin{array}{c}\text { Public Pension } \\
\text { Benefit } \\
(\text { GDP Ratio })\end{array}$ & $\begin{array}{c}\text { Health Insurance } \\
\text { Benefit } \\
\text { (GDP Ratio })\end{array}$ & $\begin{array}{l}\text { Interest } \\
\text { Rate } \\
(\%), r\end{array}$ & $n-r$ \\
\hline \multicolumn{11}{|l|}{ Actual } \\
\hline 2002 & 1.14 & 0.05 & -8.48 & 15.62 & 9.69 & 18.57 & 7.75 & 5.89 & & \\
\hline \multicolumn{11}{|c|}{ Simulation Results } \\
\hline 2003 & 1.21 & 0.73 & -3.30 & 21.14 & 9.65 & 15.12 & 10.16 & 5.06 & 3.94 & -3.20 \\
\hline 2005 & 1.34 & 0.40 & -2.43 & 22.21 & 10.18 & 15.94 & 10.73 & 5.21 & 3.59 & -3.19 \\
\hline 2010 & 1.60 & 0.04 & 0.43 & 25.70 & 11.95 & 18.71 & 12.53 & 5.67 & 2.89 & -2.85 \\
\hline 2015 & 1.71 & -0.60 & 3.46 & 29.62 & 14.24 & 22.30 & 15.20 & 6.21 & 2.29 & -2.89 \\
\hline 2020 & 1.75 & -0.57 & 4.63 & 31.35 & 15.82 & 24.78 & 16.74 & 6.70 & 2.05 & -2.63 \\
\hline 2025 & 1.75 & -0.73 & 4.72 & 31.75 & 16.60 & 26.01 & 17.42 & 7.14 & 1.95 & -2.68 \\
\hline 2030 & 1.75 & -1.11 & 5.19 & 32.62 & 17.53 & 27.45 & 18.37 & 7.62 & 1.83 & -2.93 \\
\hline 2035 & 1.75 & -1.42 & 5.55 & 33.54 & 18.91 & 29.62 & 19.87 & 8.16 & 1.70 & -3.12 \\
\hline 2040 & 1.75 & -1.59 & 5.72 & 34.54 & 21.02 & 32.93 & 22.35 & 8.66 & 1.62 & -3.22 \\
\hline 2045 & 1.75 & -1.49 & 5.78 & 35.15 & 22.42 & 35.13 & 23.85 & 9.12 & 1.76 & -3.26 \\
\hline 2050 & 1.75 & -1.46 & 6.20 & 35.93 & 23.27 & 36.44 & 24.68 & 9.59 & 2.03 & -3.49 \\
\hline
\end{tabular}

Note: The social security contribution rate is defined as the ratio of the total amount of social security contributions to the total amount of wage income. 
Table 2: Bond Outstanding (GDP Ratio)

\begin{tabular}{|c|c|c|c|c|c|c|}
\hline \multirow[t]{2}{*}{$\overline{\text { Year }}$} & \multirow[t]{2}{*}{$\overline{\text { Base }}$} & \multicolumn{2}{|c|}{ Debt } & \multicolumn{2}{|c|}{ Population } & \multirow[t]{2}{*}{$\overline{\text { Pension }}$} \\
\hline & & High & Low & High & Low & \\
\hline 2003 & 1.21 & 1.22 & 1.21 & 1.21 & 1.21 & 1.21 \\
\hline 2005 & 1.34 & 1.37 & 1.33 & 1.34 & 1.34 & 1.34 \\
\hline 2010 & 1.60 & 1.81 & 1.48 & 1.60 & 1.60 & 1.60 \\
\hline 2015 & 1.71 & 2.30 & 1.50 & 1.71 & 1.71 & 1.71 \\
\hline 2020 & 1.75 & 2.82 & 1.50 & 1.75 & 1.75 & 1.75 \\
\hline 2025 & 1.75 & 3.34 & 1.50 & 1.75 & 1.75 & 1.75 \\
\hline 2030 & 1.75 & 3.80 & 1.50 & 1.75 & 1.75 & 1.75 \\
\hline 2035 & 1.75 & 4.18 & 1.50 & 1.75 & 1.75 & 1.75 \\
\hline 2040 & 1.75 & 4.44 & 1.50 & 1.75 & 1.75 & 1.75 \\
\hline 2045 & 1.75 & 4.50 & 1.50 & 1.75 & 1.75 & 1.75 \\
\hline 2050 & 1.75 & 4.50 & 1.50 & 1.75 & 1.75 & 1.75 \\
\hline
\end{tabular}

Table 3: Primary Balance (GDP Ratio)

\begin{tabular}{cccccccc}
\hline \hline Year & \multirow{2}{*}{ Base } & \multicolumn{2}{c}{ Debt } & & \multicolumn{2}{c}{ Population } & \multirow{2}{*}{ Pension } \\
\cline { 3 - 4 } & & High & Low & & High & Low & \\
\hline 2003 & -3.30 & -3.53 & -3.32 & & -3.30 & -3.29 & -4.17 \\
2005 & -2.43 & -3.57 & -0.97 & & -2.43 & -2.41 & -3.46 \\
2010 & 0.43 & -3.73 & 2.97 & & 0.43 & 0.45 & -1.02 \\
2015 & 3.46 & -2.45 & 4.16 & & 3.46 & 3.47 & 1.68 \\
2020 & 4.63 & -1.13 & 3.78 & & 4.63 & 4.63 & 2.53 \\
2025 & 4.72 & 1.81 & 3.89 & & 4.69 & 4.74 & 2.37 \\
2030 & 5.19 & 6.25 & 4.30 & & 5.14 & 5.24 & 2.60 \\
2035 & 5.55 & 11.00 & 4.60 & & 5.47 & 5.62 & 2.72 \\
2040 & 5.72 & 15.44 & 4.75 & & 5.63 & 5.80 & 2.66 \\
2045 & 5.78 & 19.65 & 4.79 & & 5.70 & 5.86 & 2.45 \\
2050 & 6.20 & 20.94 & 5.13 & & 6.09 & 6.31 & 2.54 \\
\hline \hline
\end{tabular}

Table 4: Tax Burden (GDP Ratio)

\begin{tabular}{cccccccc}
\hline \hline \multirow{2}{*}{ Year } & \multirow{2}{*}{ Base } & \multicolumn{2}{c}{ Debt } & & \multicolumn{2}{c}{ Population } & Pension \\
\cline { 3 - 4 } & & High & Low & & High & Low & \\
\hline 2003 & 21.14 & 20.92 & 21.12 & & 21.14 & 21.15 & 20.21 \\
2005 & 22.21 & 21.08 & 23.67 & & 22.21 & 22.22 & 21.07 \\
2010 & 25.70 & 21.56 & 28.24 & & 25.69 & 25.70 & 23.99 \\
2015 & 29.62 & 23.75 & 30.31 & & 29.60 & 29.61 & 27.36 \\
2020 & 31.35 & 25.65 & 30.49 & & 31.34 & 31.33 & 28.55 \\
2025 & 31.75 & 28.93 & 30.91 & & 31.70 & 31.76 & 28.38 \\
2030 & 32.62 & 33.79 & 31.72 & & 32.51 & 32.69 & 28.65 \\
2035 & 33.54 & 39.12 & 32.59 & & 33.35 & 33.71 & 28.83 \\
2040 & 34.54 & 44.40 & 33.56 & & 34.22 & 34.88 & 28.82 \\
2045 & 35.15 & 49.16 & 34.15 & & 34.67 & 35.71 & 28.63 \\
2050 & 35.93 & 50.82 & 34.85 & 35.22 & 36.80 & 28.77 \\
\hline \hline
\end{tabular}


Table 5: Social Security Burden (GDP Ratio)

\begin{tabular}{cccccccc}
\hline \hline Year & \multirow{2}{*}{ Base } & \multicolumn{2}{c}{ Debt } & & \multicolumn{2}{c}{ Population } & Pension \\
\cline { 3 - 4 } & & High & Low & & High & Low & \\
\hline 2003 & 9.65 & 9.62 & 9.66 & & 9.63 & 9.63 & 9.82 \\
2005 & 10.18 & 10.13 & 10.18 & & 10.15 & 10.15 & 10.23 \\
2010 & 11.95 & 11.84 & 11.99 & & 11.91 & 11.91 & 11.65 \\
2015 & 14.24 & 14.08 & 14.27 & & 14.19 & 14.19 & 13.43 \\
2020 & 15.82 & 15.62 & 15.84 & & 15.76 & 15.77 & 14.47 \\
2025 & 16.60 & 16.40 & 16.62 & & 16.53 & 16.56 & 14.50 \\
2030 & 17.53 & 17.34 & 17.54 & & 17.39 & 17.57 & 14.57 \\
2035 & 18.91 & 18.75 & 18.92 & & 18.61 & 19.15 & 14.67 \\
2040 & 21.02 & 20.91 & 21.03 & & 20.41 & 21.67 & 14.82 \\
2045 & 22.42 & 22.35 & 22.43 & & 21.39 & 23.64 & 14.94 \\
2050 & 23.27 & 23.18 & 23.28 & 21.73 & 25.22 & 15.02 \\
\hline \hline
\end{tabular}

Table 6: Social Security Contribution Rate

\begin{tabular}{cccccccc}
\hline \hline \multirow{2}{*}{ Year } & \multirow{2}{*}{ Base } & \multicolumn{2}{c}{ Debt } & & \multicolumn{2}{c}{ Population } & Pension \\
\cline { 3 - 4 } & & High & Low & & High & Low & \\
\hline 2003 & 15.12 & 15.06 & 15.13 & & 15.09 & 15.08 & 15.38 \\
2005 & 15.94 & 15.86 & 15.94 & & 15.90 & 15.89 & 16.02 \\
2010 & 18.71 & 18.55 & 18.78 & & 18.65 & 18.65 & 18.25 \\
2015 & 22.30 & 22.05 & 22.36 & & 22.23 & 22.23 & 21.04 \\
2020 & 24.78 & 24.47 & 24.81 & & 24.69 & 24.70 & 22.66 \\
2025 & 26.01 & 25.68 & 26.03 & & 25.89 & 25.94 & 22.72 \\
2030 & 27.45 & 27.15 & 27.47 & & 27.24 & 27.52 & 22.82 \\
2035 & 29.62 & 29.37 & 29.63 & & 29.14 & 30.00 & 22.98 \\
2040 & 32.93 & 32.75 & 32.95 & & 31.97 & 33.94 & 23.22 \\
2045 & 35.13 & 35.00 & 35.14 & & 33.50 & 37.03 & 23.40 \\
2050 & 36.44 & 36.31 & 36.46 & & 34.04 & 39.51 & 23.53 \\
\hline \hline
\end{tabular}

Note: The social security contribution rate is defined as the ratio of the total amount of social security contributions to the total amount of wage income.

Table 7: Deviation from The Base Case of Utility

\begin{tabular}{ccccccc}
\hline \hline \multirow{2}{*}{ Year } & \multicolumn{2}{c}{ Debt } & & \multicolumn{2}{c}{ Population } & Pension \\
\cline { 2 - 3 } \cline { 5 - 6 } & High & Low & & High & Low & \\
\hline 2003 & -0.15 & 0.05 & & 0.01 & 0.01 & -1.03 \\
2005 & 0.02 & -0.33 & & 0.02 & 0.01 & -1.03 \\
2010 & 0.60 & -0.59 & & 0.04 & 0.00 & -0.99 \\
2015 & 0.86 & -0.13 & & 0.07 & -0.03 & -0.90 \\
2020 & 0.73 & 0.23 & & 0.11 & -0.09 & -0.65 \\
2025 & 0.00 & 0.23 & & 0.19 & -0.20 & -0.28 \\
2030 & -0.96 & 0.25 & & 0.31 & -0.40 & 0.18 \\
2035 & -2.05 & 0.27 & & 0.49 & -0.72 & 0.77 \\
2040 & -3.16 & 0.30 & & 0.77 & -1.20 & 1.53 \\
2045 & -4.33 & 0.33 & & 1.14 & -1.88 & 2.31 \\
2050 & -4.67 & 0.37 & & 1.61 & -2.77 & 3.07 \\
\hline \hline
\end{tabular}


Table 8: $0.5 \%$ of Annual Technological Progress, and 1\% of Annual Increase in Medical Expenses

\begin{tabular}{cccccccc}
\hline \hline Year & $\begin{array}{c}\text { GDP } \\
\text { Growth } \\
\text { Rate (\%), } n\end{array}$ & $\begin{array}{c}\text { Primary } \\
\text { Balance } \\
(\text { GDP Ratio })\end{array}$ & $\begin{array}{c}\text { Tax } \\
\text { Burden } \\
(\text { GDP Ratio })\end{array}$ & $\begin{array}{c}\text { Social Security } \\
\text { Burden } \\
(\text { GDP Ratio })\end{array}$ & $\begin{array}{c}\text { Social Security } \\
\text { Contribution rate } \\
\text { Rate }(\%)\end{array}$ & $\begin{array}{c}\text { Interest } \\
\text { Rate } \\
(\%), r\end{array}$ & $n-r$ \\
\hline Simulation Results & & & & & & \\
2003 & 1.11 & -3.03 & 21.45 & 9.63 & 15.09 & 4.57 & -3.46 \\
2005 & 0.84 & -2.01 & 22.68 & 10.16 & 15.92 & 4.37 & -3.53 \\
2010 & 0.59 & 1.18 & 26.54 & 11.99 & 18.77 & 3.93 & -3.34 \\
2015 & 0.01 & 4.40 & 30.70 & 14.37 & 22.50 & 3.48 & -3.47 \\
2020 & 0.09 & 5.72 & 32.63 & 16.04 & 25.12 & 3.36 & -3.27 \\
2025 & -0.02 & 5.88 & 33.15 & 16.92 & 26.50 & 3.34 & -3.36 \\
2030 & -0.38 & 6.39 & 34.10 & 17.96 & 28.13 & 3.26 & -3.64 \\
2035 & -0.68 & 6.77 & 35.09 & 19.47 & 30.50 & 3.16 & -3.84 \\
2040 & -0.85 & 6.97 & 36.18 & 21.72 & 34.02 & 3.10 & -3.95 \\
2045 & -0.74 & 7.11 & 36.92 & 23.25 & 36.42 & 3.29 & -4.03 \\
2050 & -0.71 & 7.60 & 37.83 & 24.22 & 37.94 & 3.61 & -4.31 \\
\hline \hline
\end{tabular}

Note: The social security contribution (GDP ratio) is defined as the ratio of the total amount of social security contributions to the total amount of wage income.

Table 9: 1\% of Annual Technological Progress, and 1\% of Annual Increase in Medical Expenses

\begin{tabular}{cccccccc}
\hline \hline Year & $\begin{array}{c}\text { GDP } \\
\text { Growth } \\
\text { Rate (\%), } n\end{array}$ & $\begin{array}{c}\text { Primary } \\
\text { Balance } \\
(\text { GDP Ratio })\end{array}$ & $\begin{array}{c}\text { Tax } \\
\text { Burden } \\
(\text { GDP Ratio })\end{array}$ & $\begin{array}{c}\text { Social Security } \\
\text { Burden } \\
\text { (GDP Ratio })\end{array}$ & $\begin{array}{c}\text { Social Security } \\
\text { Contribution rate } \\
\text { Rate }(\%)\end{array}$ & $\begin{array}{c}\text { Interest } \\
\text { Rate } \\
(\%), r\end{array}$ & $n-r$ \\
\hline \multicolumn{2}{r}{ Simulation } & Results & & & & & \\
2003 & 1.39 & -2.33 & 22.17 & 9.46 & 14.81 & 5.48 & -4.09 \\
2005 & 1.19 & -1.05 & 23.66 & 9.91 & 15.52 & 5.49 & -4.30 \\
2010 & 1.07 & 2.75 & 28.10 & 11.53 & 18.07 & 5.45 & -4.38 \\
2015 & 0.58 & 6.37 & 32.61 & 13.72 & 21.48 & 5.24 & -4.66 \\
2020 & 0.72 & 8.02 & 34.80 & 15.16 & 23.74 & 5.33 & -4.61 \\
2025 & 0.65 & 8.36 & 35.42 & 15.80 & 24.74 & 5.46 & -4.81 \\
2030 & 0.33 & 8.98 & 36.40 & 16.57 & 25.96 & 5.48 & -5.15 \\
2035 & 0.04 & 9.42 & 37.35 & 17.80 & 27.87 & 5.43 & -5.39 \\
2040 & -0.12 & 9.71 & 38.41 & 19.73 & 30.90 & 5.42 & -5.54 \\
2045 & 0.00 & 9.98 & 39.15 & 20.91 & 32.75 & 5.70 & -5.70 \\
2050 & 0.05 & 10.61 & 40.07 & 21.51 & 33.69 & 6.11 & -6.07 \\
\hline \hline
\end{tabular}

Note: The social security contribution (GDP ratio) is defined as the ratio of the total amount of social security contributions to the total amount of wage income.

Table 10: 1\% of Annual Technological Progress, and 0\% of Annual Increase in Medical Expenses

\begin{tabular}{cccccccc}
\hline \hline Year & $\begin{array}{c}\text { GDP } \\
\text { Growth } \\
\text { Rate }(\%), n\end{array}$ & $\begin{array}{c}\text { Primary } \\
\text { Balance } \\
\text { (GDP Ratio })\end{array}$ & $\begin{array}{c}\text { Tax } \\
\text { Burden } \\
(\text { GDP Ratio })\end{array}$ & $\begin{array}{c}\text { Social Security } \\
\text { Burden } \\
(\text { GDP Ratio })\end{array}$ & $\begin{array}{c}\text { Social Security } \\
\text { Contribution rate } \\
\text { Rate }(\%)\end{array}$ & $\begin{array}{c}\text { Interest } \\
\text { Rate } \\
(\%), r\end{array}$ & $n-r$ \\
\hline Simulation & Results & & & & & & \\
2003 & 1.33 & -2.02 & 22.48 & 9.34 & 14.62 & 5.69 & -4.36 \\
2005 & 1.14 & -0.67 & 24.01 & 9.70 & 15.20 & 5.73 & -4.60 \\
2010 & 1.03 & 3.28 & 28.52 & 11.11 & 17.40 & 5.75 & -4.72 \\
2015 & 0.55 & 7.00 & 33.04 & 13.05 & 20.44 & 5.58 & -5.03 \\
2020 & 0.70 & 8.70 & 35.19 & 14.24 & 22.30 & 5.70 & -5.00 \\
2025 & 0.64 & 9.06 & 35.73 & 14.62 & 22.91 & 5.85 & -5.21 \\
2030 & 0.33 & 9.67 & 36.60 & 15.14 & 23.72 & 5.87 & -5.54 \\
2035 & 0.05 & 10.08 & 37.42 & 16.10 & 25.22 & 5.81 & -5.77 \\
2040 & -0.11 & 10.34 & 38.34 & 17.77 & 27.84 & 5.79 & -5.90 \\
2045 & 0.02 & 10.57 & 38.95 & 18.71 & 29.30 & 6.06 & -6.04 \\
2050 & 0.07 & 11.16 & 39.73 & 19.06 & 29.85 & 6.46 & -6.38 \\
\hline \hline
\end{tabular}

Note: The social security contribution (GDP ratio) is defined as the ratio of the total amount of social security contributions to the total amount of wage income. 